TAO, Vol. 17, No. 1, 23-52, March 2006

\title{
Numerical Simulation of Typhoon Dot (1990) during TCM-90: Typhoon Dot's Discontinuous Track Across Taiwan
}

\author{
Guo-Ji Jian ${ }^{1, *}$, Cheng-Shang Lee ${ }^{2}$, and George Tai-Jen Chen ${ }^{2}$
}

(Manuscript received 1 October 2003, in final form 20 December 2003)

\begin{abstract}
A numerical simulation associated with Typhoon Dot (1990) was made using the fifth-generation Pennsylvania State University - National Center for Atmospheric Research Mososcale Model (MM5) initialized with data from the Tropical Cyclone Motion (TCM-90) field experiment. The physical processes which occurred during the discontinuous track of Typhoon Dot over Taiwan are investigated.

Observational and numerical results show that a region of low pressure developed over the central part of western Taiwan, induced primarily by strong adiabatic warming on the leeside of the Central Mountain Range (CMR) associated with the downslope easterly winds of the typhoon. A few hours later, a dominant leeside secondary vortex formed via a vortex stretching process over southwestern Taiwan with the original low-level vortex of Dot being blocked and weakened, and gradually dissipating on the eastern side of the CMR. The region of low pressure was larger than the final stretched induced secondary vortex. During the dominant secondary vortex formation, a leeside low-pressure center shifted southwestward and merged with a low-level vorticity center over the southwestern coast of Taiwan. Simulation results also indicate that the mid-level vortex of Dot passed over Taiwan with a continuous track, and then interacted with the dominant secondary vortex over southwestern Taiwan. Finally, the midlevel and secondary vortices coupled vertically and appeared to reestablish Typhoon Dot's contiguous vertical structure as it continued its northwest journey.
\end{abstract}

(Key words: Typhoon, Discontinuous track, MM5, TCM-90)

\footnotetext{
${ }^{1}$ Central Weather Bureau, Taipei, Taiwan, ROC

2 Department of Atmospheric Sciences, National Taiwan University, Taipei, Taiwan, ROC

* Corresponding author address: Dr. Guo-Ji Jian, Central Weather Bureau, Taipei, Taiwan, ROC; E-mail: jgj@mfcsv.cwb.gov.tw
} 


\section{INTRODUCTION}

Taiwan is frequently affected by tropical cyclones with an average of 3.6 events annually (Shieh et al. 1998). Due to the dramatic devastation brought by these storms, typhoons are the most dangerous weather systems in the Taiwan area.

As a typhoon approaches Taiwan, the Central Mountain Range (CMR; Fig. 1) plays an important role in deflecting the storm track, producing local circulation variations, and many heavy orographic rainfall events (Wu and Kuo 1999). Observational analyses of typhoon tracks made by Wang (1980) indicated that westward-moving typhoons with continuous tracks tended to deflect southward upstream of Taiwan, and then move cyclonically over the CMR. Meteorological factors and processes related to this track deflection have been studied extensively by numerical simulations, including: storm intensity and translation speed (Bender et al. 1987; Yeh and Elsberry 1993a), blocking and channeling flows (Lin et al. 1999), and modification of the steering flows (Chang 1982; Bender et al. 1987; Wu 2001). Utilizing various factors from previous studies, Lin et al. (2002) and Lin et al. (2005) identified control parameters for storm track continuity and deflection over Taiwan. They found that when values of the vortex Froude number and the ratio of vortex scale to mountain scale are simultaneously large enough, the track of a tropical cyclone tends to be continuous. Otherwise, the storm's track tends to be discontinuous. For a tropical cyclone with discontinuous path, both observational (Wang 1980; Du and Chen 1992) and numerical studies (Bender et al. 1987; Yeh and Elsberry 1993b) showed that two or more secondary vortices could form over the leeside of the CMR, especially for a weak or slow-moving storm. One of these secondary vortices could subsequently develop and replace the original vortex to become the main typhoon center. As for precipitation, although rainfall distribution for a typhoon affecting Taiwan is often phase-locked with the CMR (Chang et al. 1993), accurate forecasts of mesoscale precipitation distribution associated with such rainbands still presents a great challenge for numerical weather prediction (Wu 2001).

In order to understand the complicated physical mechanisms occurring during typhoons affecting Taiwan, some insightful real-case numerical studies (Kuo and Wang 1997; Wu 2001; Wu et al. 2002; Lin et al. 2002) have been undertaken. These have demonstrated that the highresolution nonhydrostatic model is capable of simulating detailed local circulation variations. However, a lack of mesoscale observations, providing finer descriptions of storms, is still a major limitation in typhoon simulations. Owing to the importance of dense observational data for tropical cyclone research, the Tropical Cyclone Motion (TCM-90) field experiment (Elsberry 1990) in the western North Pacific area was carried out during August and September 1990 by the United States, the Economic and Social Commission for Asia, the Pacific/World Meteorological Organization (ESCAP/WMO) Typhoon Committee, Taiwan, and the former Soviet Union. The TCM-90 field experiment was designed to better understand tropical cyclone motion, the effects of ocean inhomogeneities on tropical cyclones, the response of the ocean to typhoon passage, and to improve operational storm track prediction. Furthermore, scientists in Taiwan set up special observations for typhoons approaching Taiwan.

In this study, we apply TCM-90 datasets, using the fifth-generation Pennsylvania State University - National Center for Atmospheric Research Mesoscale Model (MM5), to diagnose the physical processes occurring during Typhoon Dot's discontinuous transit of Taiwan in 


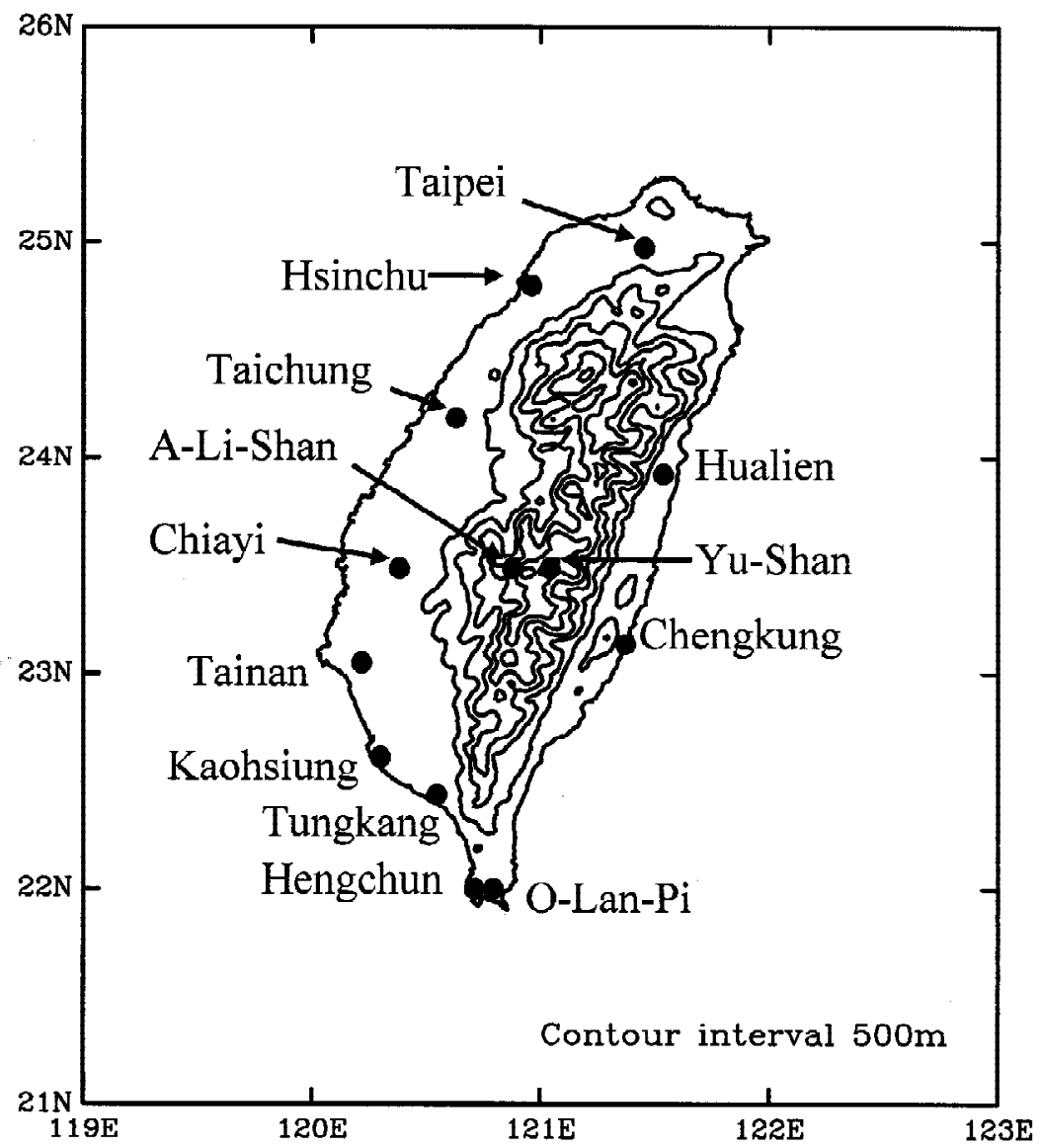

Fig. 1. Terrain map of Taiwan. Contours are drawn from $500 \mathrm{~m}$ high with an interval of $500 \mathrm{~m}$. The filled circles indicate the locations of Taipei, Hsinchu, Taichung, A-Li-Shan, Chiayi, Tainan, Kaohsiung, Tungkang, Hengchu, Hualien, Yu-Shan, Chengkung, and O-Lan-Pi stations.

1990. Typhoon Dot was selected because it was one of two typhoons that made landfall on Taiwan during the TCM-90 field experiment [the other was Typhoon Yancy (1990); Jian and Lee (2002)]. During the period when Dot passed over Taiwan, 3-h soundings were launched at three in situ sites [Taipei $\left(25.0^{\circ} \mathrm{N}, 121.5^{\circ} \mathrm{E}\right)$, Hualien $\left(23.9^{\circ} \mathrm{N}, 121.6^{\circ} \mathrm{E}\right)$, and Tungkang $\left(22.4^{\circ} \mathrm{N}, 120.4^{\circ} \mathrm{E}\right)$; see Fig. 1], and two mobile stations [Taichung $\left(24.1^{\circ} \mathrm{N}, 120.7^{\circ} \mathrm{E}\right)$ and O-Lan-Pi $\left(21.9^{\circ} \mathrm{N}, 120.9^{\circ} \mathrm{E}\right)$; see Fig. 1]. Moreover, enhanced surface and radar observations were also collected to provide a better description of mesoscale circulation and rainfall distributions. According to the observational analyses of Du and Chen (1992), Tsay et al. (1995), and Shieh et al. (1998), Typhoon Dot passed over Taiwan discontinuously by regenerating a new typhoon center on the leeside of the CMR. In this paper, we address the physical 
mechanisms of this scientific phenomenon through high-resolution numerical simulation. In the following section, the life history of Dot is discussed. Section 3 presents the mesoscale model configuration, initial data, and experiment design. In section 4, the physical processes of Dot's secondary vortex formation are discussed. Section 5 explores the interaction between mid-level and secondary vortices during Dot's passage over Taiwan. Discussion and conclusions follow in section 6 . The last section is an appendix that shows the results of varying convective adjustment parameters in the Betts-Miller cumulus parameterization scheme (Betts 1986; Betts and Miller 1986) to examine their impact on typhoon intensity and movement in the numerical simulations.

\section{SYNOPTIC DESCRIPTION OF TYPHOON DOT}

Typhoon Dot originated from a disturbance that formed over the western North Pacific in early September 1990. According to the official report of the Central Weather Bureau (CWB) in Taiwan, it was designated a tropical storm at 1200 UTC 4 September, and a typhoon at 0000 UTC 6 September. Figure 2a shows the best estimated track of Dot from 6 to 8 September. It moved northwestward along the southern edge of a subtropical high and reached its maximum intensity at 1800 UTC 6 September with an estimated maximum sustained wind of $38 \mathrm{~m} \mathrm{~s}^{-1}$ near the center and a minimum sea level pressure of $960 \mathrm{hPa}$. Dot followed a very straight track as it approached Taiwan and made landfall on the shoreline near Chengkung $\left(23.1^{\circ} \mathrm{N}\right.$, $121.4^{\circ} \mathrm{E}$; see Fig. 1 for location) at around 1400 UTC 7 September.

During the period when Dot passed over Taiwan, the mean sea-level pressure and local circulation analyses (Fig. 3; after Tsay et al. 1995) based on surface observations show that there were two secondary low-pressure centers near central and southwestern Taiwan. A few hours later, a dominant secondary vortex developed in the vicinity of southwestern Taiwan. It subsequently replaced the original typhoon center becoming Dot's new center after the storm made landfall on Taiwan. The new typhoon center then moved toward the Taiwan Strait and executed an interesting cyclonic looping track (Tsay et al. 1995; Shieh et al. 1998; see Fig. 2a). The physical mechanisms of these interesting features will be examined through a high-resolution MM5 simulation in the following sections. After making the looping track, Dot veered northwestward and made landfall over Mainland China. Owing to strong surface friction and smaller surface heat fluxes over land, Dot weakened to a tropical storm at 0600 UTC 8 September and then to a tropical depression at 0600 UTC 9 September.

\section{MODEL CONFIGURATION AND EXPERIMENT DESIGN}

The PSU-NCAR MM5 (Dudhia 1993; Grell et al. 1994) was configured in nonhydrostatic mode for the Typhoon Dot simulation. The domains, shown in Fig. 4a, were two stationary $15-\mathrm{km}(181 \times 181)$ and $5-\mathrm{km}(82 \times 100)$ domains nested within a $45-\mathrm{km}(121 \times 121)$ domain using two-way interfaces. All three domains extended in the vertical to $100 \mathrm{hPa}$ and were resolved by 23 unevenly spaced sigma levels, with the finest resolution near the boundary layer. Figure $4 \mathrm{~b}$ shows Taiwan's topography in the 5-km domain, defined from 1-km resolu- 
(a) Best track of Typhoon Dot

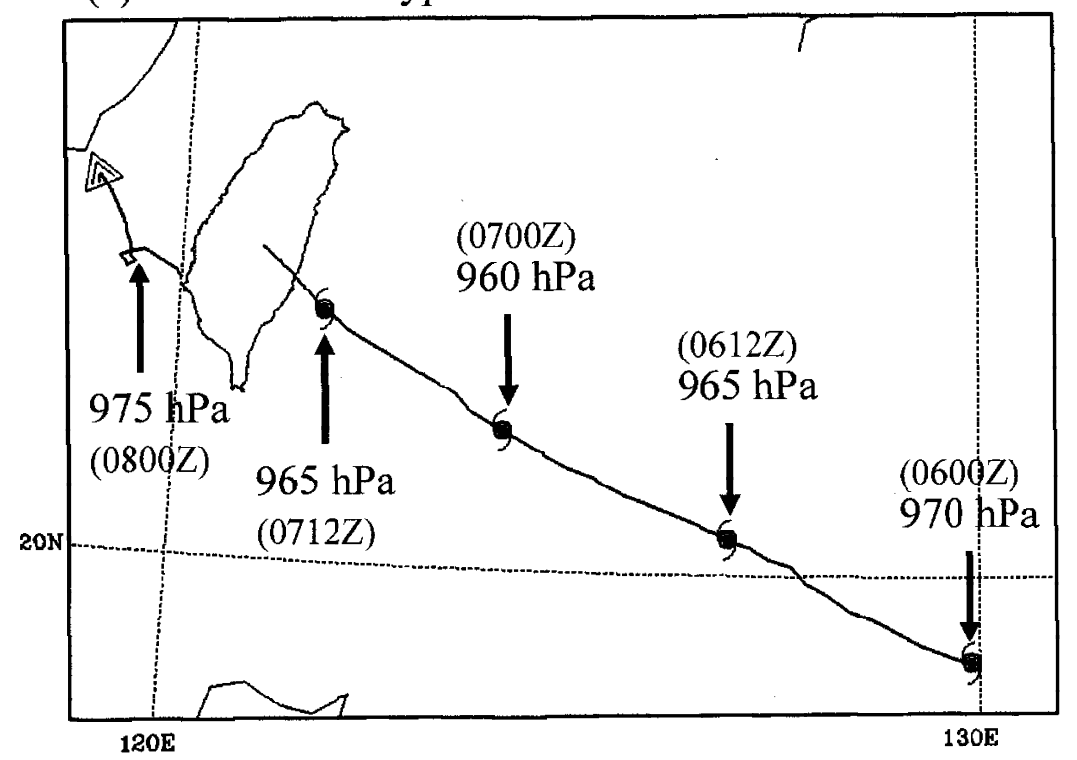

(b) Simulated track

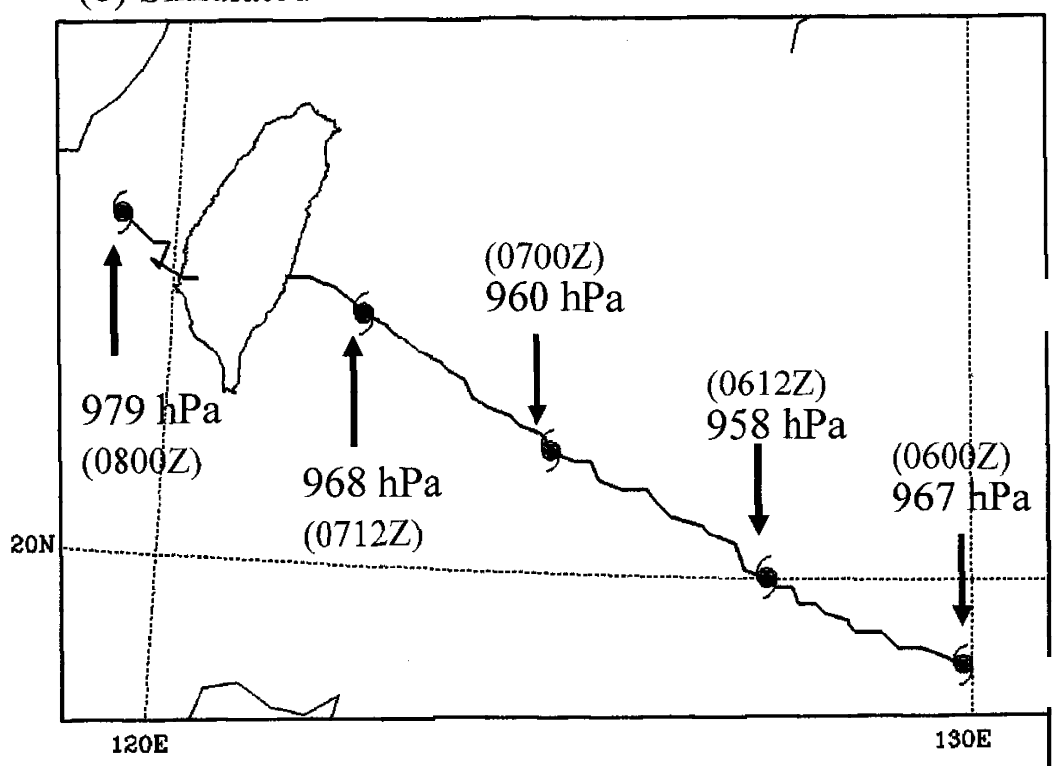

Fig. 2. (a) Best track of Typhoon Dot (1990) between 6 September and 8 September 1990. (b) The simulated typhoon track. The minimum sea-level pressure (hPa) from (a) CWB estimates, and (b) numerical simulation are also shown at 12-h intervals. 

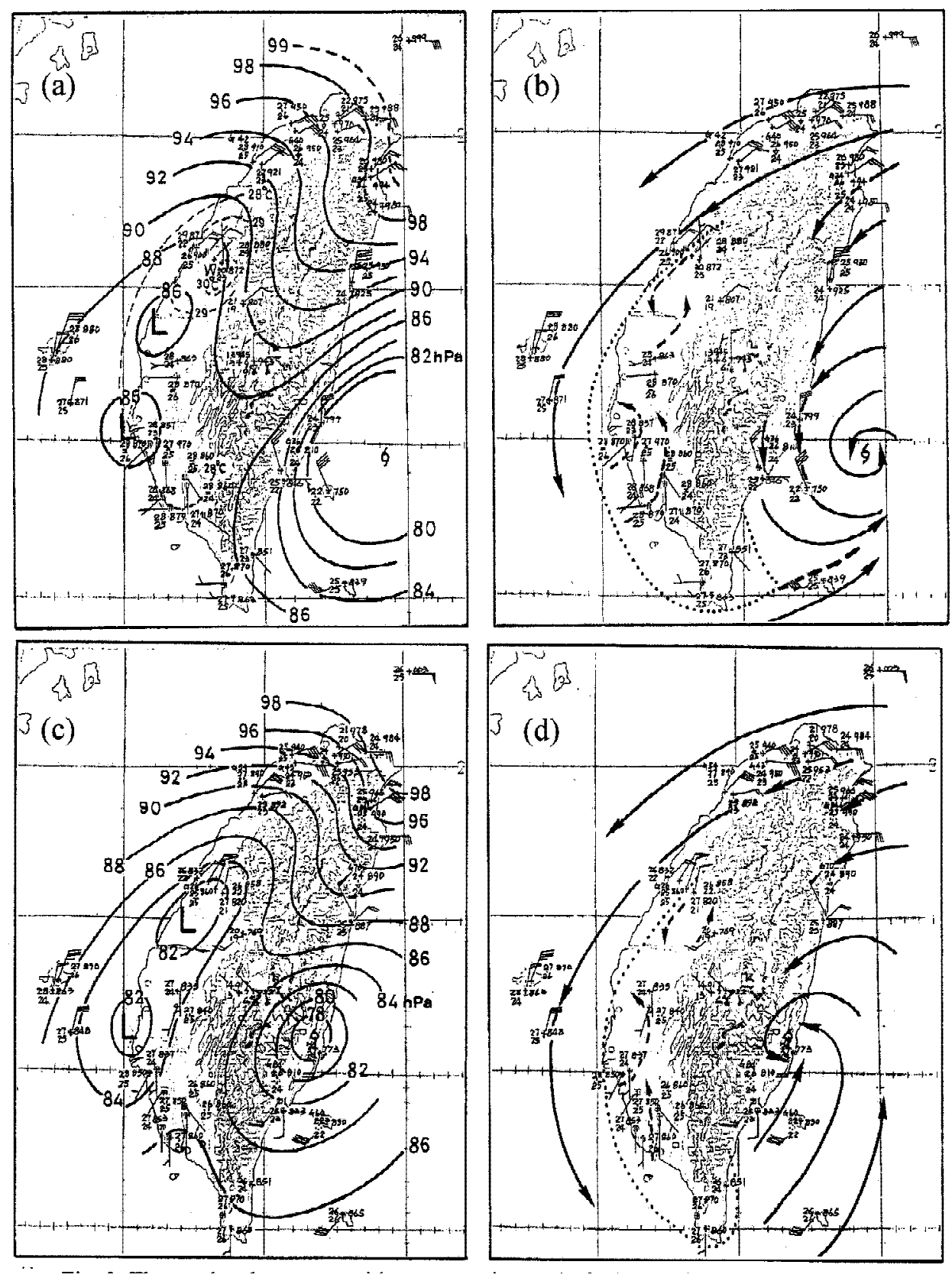

Fig. 3. The sea-level pressure with a contour interval of $2 \mathrm{hPa}$ and corresponding surface streamlines of Typhoon Dot (1990) at (a), (b) 1200 UTC 7 September, (c), (d) 1400 UTC 7 September, and (e), (f) 1600 UTC 7 September (After Tsay et al. 1995). 

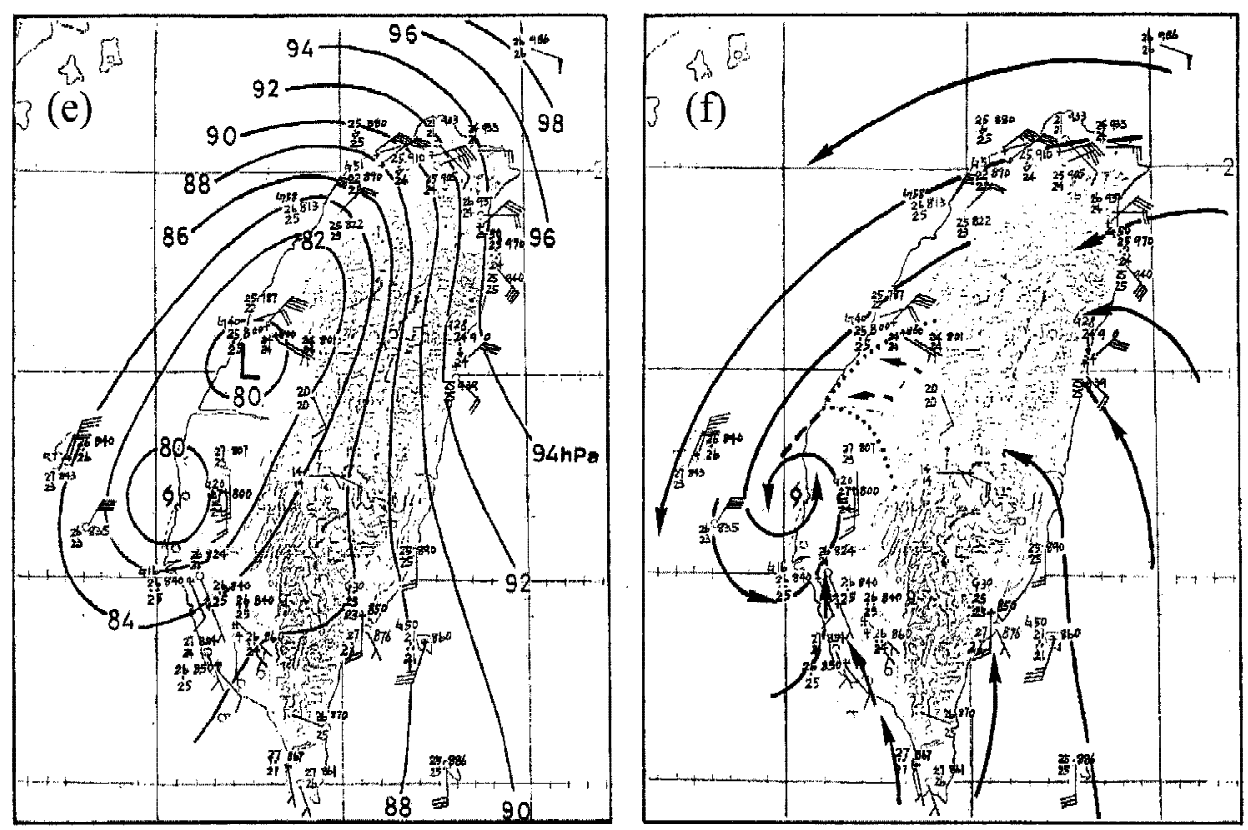

Fig. 3. (Continued)

tion terrain datasets, indicating a close correspondence to the real geography (Fig. 1). Fiveminute-averaged terrain data were analyzed to model grids using a Cressman (1959) analysis scheme and filtered by a two-pass smoother/desmoother. For various land surface categories and coastline, a five-minute-averaged land-use and land-water mask datasets from the U.S. Geological Survey were used. For the microphysics, the simple ice scheme proposed by Dudhia (1989) was utilized, which includes prognostic equations for cloud water, cloud ice, and rain. The Betts-Miller cumulus parameterization scheme (Betts 1986; Betts and Miller 1986) was applied in the $45-\mathrm{km}$ and $15-\mathrm{km}$ domains, while no cumulus scheme was used in the $5-\mathrm{km}$ domain. The planetary boundary layer (PBL) physics were parameterized using the high-resolution Blackadar PBL scheme (Blackadar 1979; Zhang and Anthes 1982). For the radiation processes, the atmospheric radiation scheme of Dudhia (1989) was utilized.

The initial and lateral boundary conditions were provided by the final analyses of the TCM-90 field experiment. Data area covered between $7.5^{\circ} \mathrm{S}$ and $48.0^{\circ} \mathrm{N}, 80.0^{\circ} \mathrm{E}$ and $173.5^{\circ} \mathrm{E}$ with 112 grid points in the meridional direction, and 188 grid points in the zonal direction $\left(0.5^{\circ} \times 0.5^{\circ}\right.$ horizontal resolution). Vertically, there were 19 levels with a 50 -hPa spacing ranging from $1000 \mathrm{hPa}$ through $100 \mathrm{hPa}$ and a surface layer. On these background grids, the atmospheric state variables, vertical velocities, and surface variables were available at 6-h intervals. The sea surface temperature (SST) was acquired from the weekly mean SST at the National Centers for Environmental Prediction (NCEP) and fixed for the entire model integration.

Following Kuo and Wang (1997) and Wu et al. (2002), the typhoon structure at the initial 


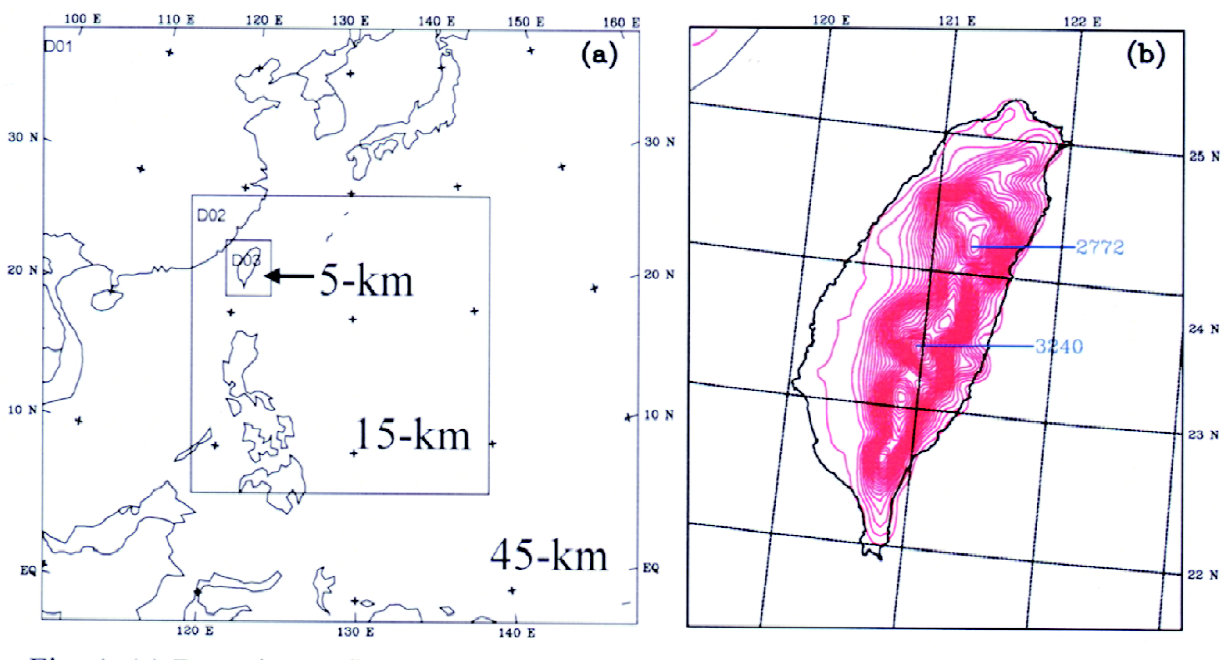

Fig. 4. (a) Domain configuration for MM5 simulations. Three domains (45-km, $15-\mathrm{km}$, and 5-km) are adopted. (b) The Taiwan topography on finest $(5-\mathrm{km})$ mesh (the 1-km terrain datasets are interpolated to the grids in this study). Contours are drawn with an interval of $100 \mathrm{~m}$.

time was initialized by bogussing, spinup, and replacing procedures. In this study, a bogussed Rankine vortex estimated from the best-track analysis of the CWB in Taiwan was used to spinup the vortex structure in a preliminary MM5 simulation, staring at 0000 UTC 5 September 1990. When the balanced vortex produced by the model (after a 24-hour integration) maintains an intensity (here, a minimum sea-level pressure of $967 \mathrm{hPa}$ ) similar to the analyses from the CWB (minimum sea-level pressure of $970 \mathrm{hPa}$ ), the 400-km-radius inner area of the asymmetric balanced vortex was taken out of the preliminary simulation and merged smoothly with the TCM-90 analyzed data and placed according to the best-estimated-track storm location at 0000 UTC 6 September 1990.

The numerical simulation of Typhoon Dot was initialized at 0000 UTC 6 September 1990 and integrated for 48 hours. For the parameterization of deep convection, Betts and Miller (1986) have defined three adjustment parameters, namely, the stability weight (specified as 0.95 in this study), which determines the slope of reference temperature profiles with respect to the moist adiabat; the saturation pressure departure $(S)$ values, which are the measure of subsaturation; and the adjustment time scale $(\tau)$, which decides the time lag between largescale forcing and convective adjustment. The reference moisture profiles are constructed using the reference temperature profiles and $\mathrm{S}$ values at three characteristic levels [cloud bottom $\left(S_{\mathrm{b}}\right)$, freezing level $\left(\mathrm{S}_{\mathrm{f}}\right)$, and cloud top $\left.\left(\mathrm{S}_{\mathrm{t}}\right)\right]$. In this study, the values of $\left(\mathrm{S}_{\mathrm{b}}, \mathrm{S}_{\mathrm{f}}, \mathrm{S}_{\mathrm{t}}, \tau\right)$ were specified as $(-48 \mathrm{hPa},-60 \mathrm{hPa},-36 \mathrm{hPa}, 1 \mathrm{~h})$. Sensitivity tests of the modeled typhoon behavior as a function of other values for convective adjustment parameters will be presented in the appendix. 


\section{NUMERICAL SIMULATION OF TYPHOON DOT}

\subsection{Track and Intensity}

A comparison of typhoon tracks from the simulation and best analyses of the CWB are shown in Figs. $2 \mathrm{a}$ and $\mathrm{b}$. In general, the model typhoon shows a very similar track to the actual storm throughout the 48-h simulation. The landfall location and the behavior of the discontinuous track with a secondary vortex developing over the southwestern part of the island also agree quite well with the analyses by Tsay et al. (1995). However, because the model vortex translates slower than the analyzed one in the first 12-h integration (the model spinup period), it makes landfall on Taiwan two-hours later than the observed storm.

As for typhoon intensity, time series of the minimum sea-level pressure and maximum surface wind from the simulation and subjective analyses are shown in Fig. 5. The simulated maximum wind speed was determined from the 150-km-radius inner area of the typhoon in the 15-km model domain. According to the analyses from the CWB and Joint Typhoon Warning Center (JTWC), Dot reached its maximum intensity about $14 \mathrm{~h}$ before landfall, which is similar to the estimate of Brand and Blelloch (1974) of $12 \mathrm{~h}$ and Wu's (2001) result of $10 \mathrm{~h}$ from Typhoon Gladys's simulation. In general, the evolution of simulated storm strength is reasonable though the maximum surface wind speeds are higher than those from the CWB and JTWC (Fig. 5b). These differences may be in part from the different definition of the sustained surface wind in the CWB (10-min-averaged wind) and JTWC (1-min-averaged wind). Overall, numerical results showed a well-simulated movement and intensity during its passage over Taiwan.

Lin et al. (2002) and Lin et al. (2005) proposed the control parameters for determining track continuity of tropical cyclones passing over Taiwan's CMR. They found that track continuity is strongly linked to $V_{\max } / N h$ and $R / L_{y}$, where $V_{\max }$ and $R$ are the maximum tangential wind speed and radius of maximum wind of a tropical cyclone, respectively; $N$ the BruntVäisälä frequency; $h$ the maximum mountain height; and $L_{y}$ the mountain horizontal scale in $y$ direction. Physically, $V_{\max } / N h$ represents the vortex Froude number of the air stream associated with the typhoon tangential circulation and $R / L_{y}$ is a measure of the ratio of typhoon scale to mountain scale. Through a systematic analysis by Lin et al. (2005), it was demonstrated that when the control parameters are simultaneously large $\left(V_{\max } / N h>1.6\right.$ and $R / L_{y}>$ $0.66)$ then the track of a tropical cyclone is continuous. Otherwise, the track is discontinuous due to strong topographic blocking. In this Typhoon Dot case study, we made estimates of the above two control parameters with $V_{\max }=45 \mathrm{~m} \mathrm{~s}^{-1}, \mathrm{~N}=1.0 \times 10^{-2} \mathrm{~s}^{-1}, h=3.0 \mathrm{~km}, R=100$ $\mathrm{km}$, and $L_{y}=180 \mathrm{~km}$. The simulated storm has $V_{\max } / N h=1.50$ and $R / L_{y}=0.56$. Thus, the flow falls into the discontinuous track regime, which is consistent with the simulated track shown in Fig. $2 b$.

\subsection{Mesoscale Analyses - Secondary Vortex Formation}

On the basis of the reasonable simulation in Dot's track and intensity, the emphases in this subsection will be to understand typhoon structure modifications associated with its discon- 

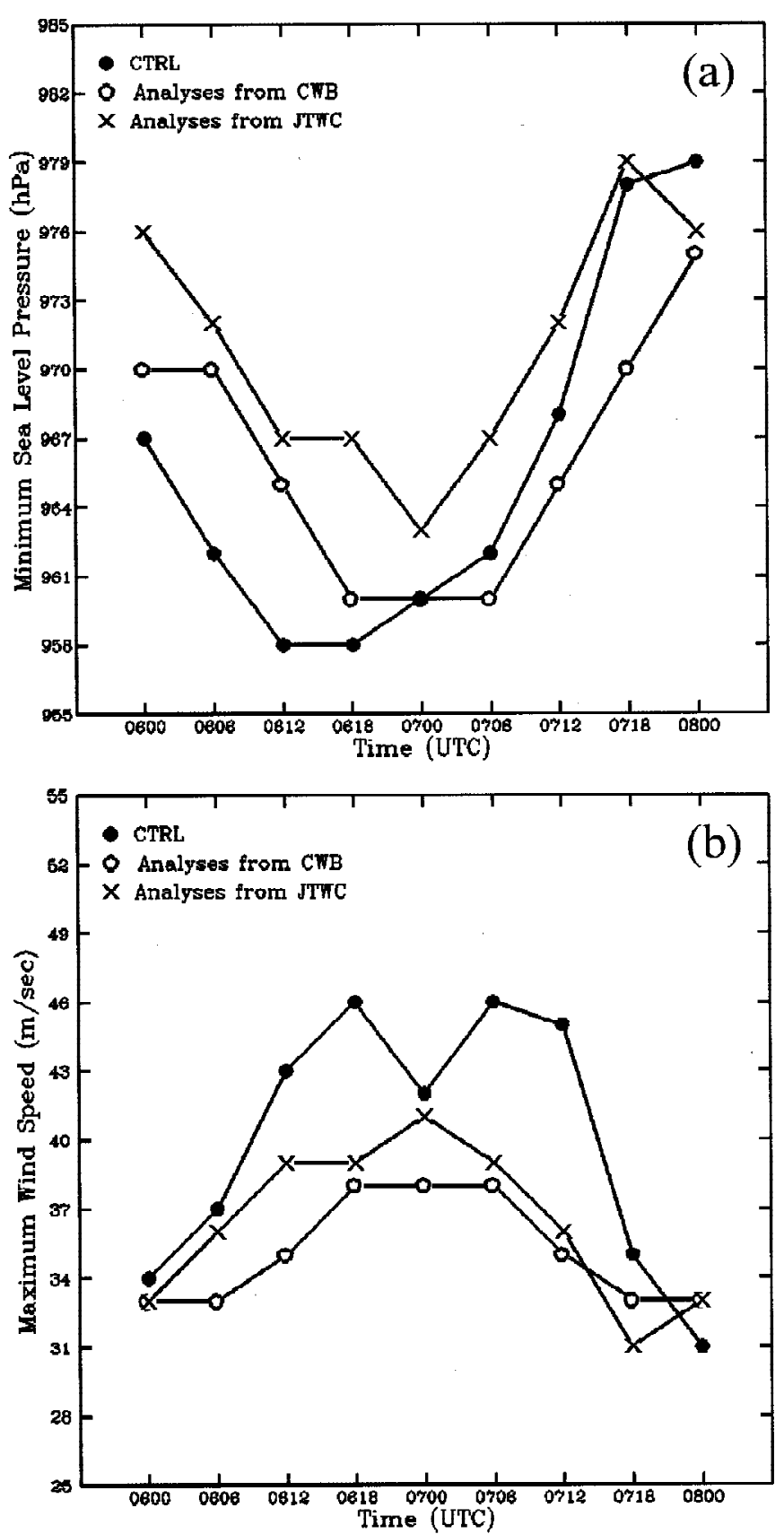

Fig. 5. (a) Minimum sea-level pressure (in $\mathrm{hPa}$ ), and (b) maximum wind speed near surface (in m s${ }^{-1}$ ) for Typhoon Dot (1990) at 6-h intervals from CWB (open circles) and JTWC (cross signs) analyses, and the numerical simulation (filled circles). 
tinuous track and the formation processes of the secondary vortex. Following the definition by Lin et al. (1999), we assume that a low-pressure center and a vorticity center are considered present when a closed isobar and a closed circulation can be analyzed in the pressure and wind fields, respectively. A vortex (cyclone) is defined if both a low-pressure center and a vorticity center exist and are collocated.

The low-level mean streamlines, defined by the average from the 0.995 to 0.87 sigma levels, in the finest mesh at 2-h intervals (the time between $34 \mathrm{~h}$ and $44 \mathrm{~h}$ ) are shown in Fig. 6. During the typhoon's approach toward the CMR (Figs. 6a - c), most of the flow near Taiwan is blocked and forced to go around the topography. When the storm makes landfall at $40 \mathrm{~h}$ (Fig. 6d), there exists two secondary vorticity centers on the western side of the CMR, one over central Taiwan, and the other located over southwestern Taiwan. At later times (Figs. 6e, f), the original low-level vortex is blocked, weakened, and gradually dissipates on the eastern side of the mountain. A new dominant secondary vortex, initiates over southwestern Taiwan, then develops and propagates toward the Taiwan Strait. Figure 7 shows the evolution of the simulated low-level mean wind vectors and mean sea level pressure every hour during the storm's transit across the island. At $39 \mathrm{~h}$ (Fig. 7a), a low-pressure center formed over central Taiwan but is not collocated with the vorticity center. At $40 \mathrm{~h}$ (Fig. 7b), a northeast-southwest-oriented lee trough is superpositioned over the weak wind area (the wake zone; see Fig. 3) on the western side of the CMR. At later times (Figs. 7c - f), the low-pressure center shifts southwestward and collocates with the dominant secondary vortex. During this stage, the easterly flow north of the island and northeasterly winds over the Taiwan Strait are much stronger than the flow on the south side of the island, which backs from westerly at $39 \mathrm{~h}$ to southwesterly after $42 \mathrm{~h}$.

A time section comparison between observed and simulated sea-level pressure for $7 \mathrm{Sep}-$ tember 1990 along the west coast, from a line of north-south oriented surface stations including Taipei $\left(25.0^{\circ} \mathrm{N}, 121.5^{\circ} \mathrm{E}\right)$, Hsinchu $\left(24.8^{\circ} \mathrm{N}, 121.0^{\circ} \mathrm{E}\right)$, Taichung $\left(24.1^{\circ} \mathrm{N}, 120.7^{\circ} \mathrm{E}\right)$, Chiayi $\left(23.5^{\circ} \mathrm{N}, 120.4^{\circ} \mathrm{E}\right)$, Tainan $\left(23.0^{\circ} \mathrm{N}, 120.2^{\circ} \mathrm{E}\right)$, Kaohsiung $\left(22.6^{\circ} \mathrm{N}, 120.3^{\circ} \mathrm{E}\right)$, and Hengchun $\left(22.0^{\circ} \mathrm{N}, 120.7^{\circ} \mathrm{E}\right)$ is shown in Fig. 8 (see Fig. 1. for locations). As Dot approached Taiwan, the observed sea-level pressure decreases with a minimum of $979 \mathrm{hPa}$ near Taichung at around 1500 UTC 7 September (Fig. 8a). However, the simulated sea-level pressure reaches a minimum value of $975 \mathrm{hPa}$ at around 1700 UTC 7 September. It is worth mentioning that the southwestward shift of the minimum pressure area on the leeside of the CMR during the secondary vortex formation (between 1500 UTC and 2000 UTC 7 September) was well simulated by the model. In general, the local circulation variations shown in Figs. 6, 7, and 8 are in good agreement with results obtained in previous studies (Du and Chen 1992; Tsay et al. 1995) during Dot's encounter with Taiwan.

As shown in Figs. 3 and 7, the region of low pressure formed on the leeside of the CMR before the typhoon made landfall on Taiwan's east coast. To diagnose the formation mechanisms, the time-height cross sections of temperature and relative humidity averaged over the region near the low-pressure center (the square box indicated in Fig. 7a) are shown in Fig. 9. It is found that the temperature (Fig. 9a) above $1.5 \mathrm{~km}$ increases about $8 \mathrm{~h}$ before landfall and reaches maximum values at around $37 \mathrm{~h}$ in the simulation. Below $1.5 \mathrm{~km}$, a steady warming tendency is present before the typhoon makes landfall. Figure $9 \mathrm{~b}$ shows that the 

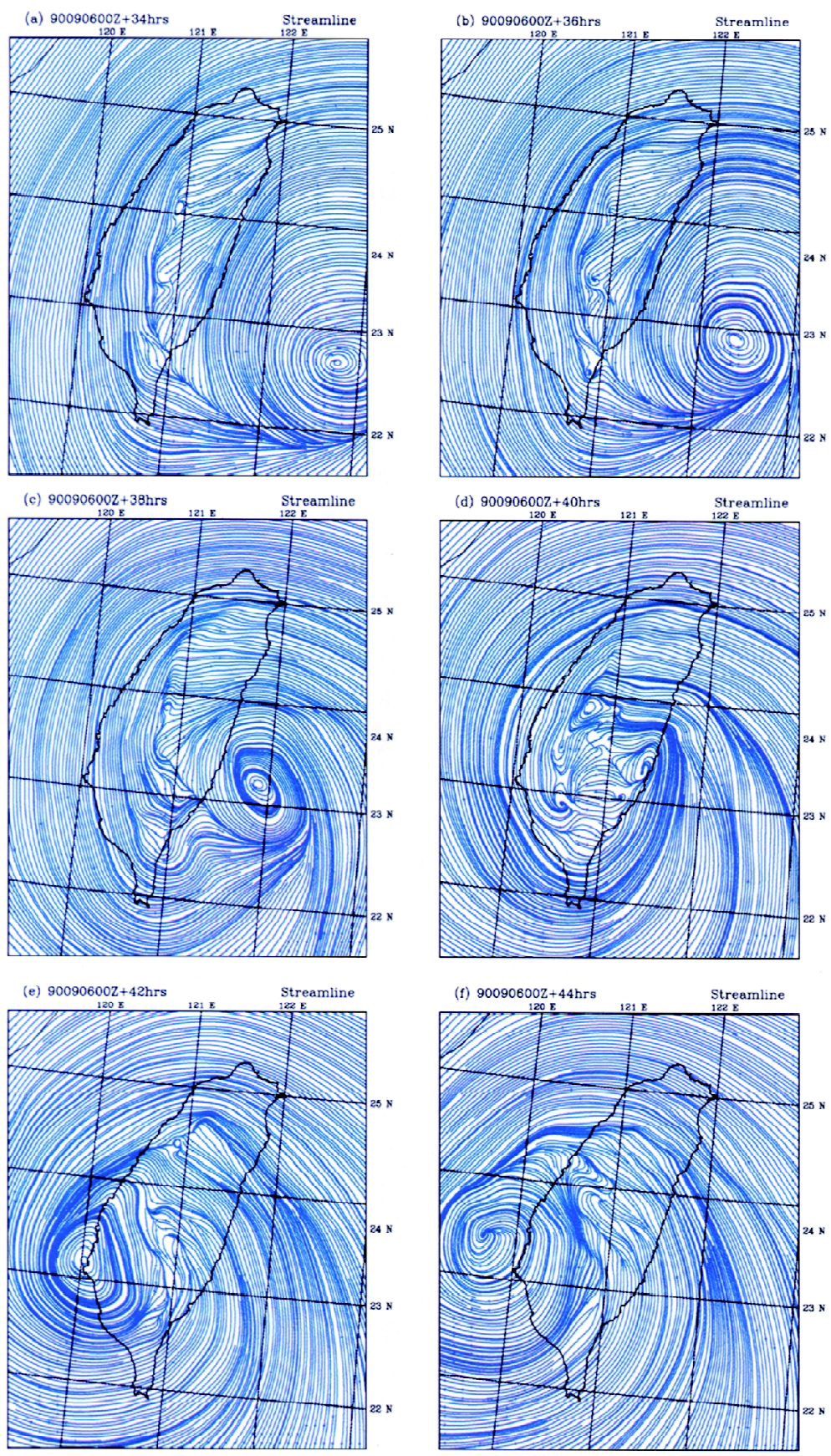

Fig. 6. The simulated low-level streamlines from the finest $(5-\mathrm{km})$ mesh at (a) $34 \mathrm{~h}$, (b) $36 \mathrm{~h}$, (c) $38 \mathrm{~h}$, (d) $40 \mathrm{~h}$, (e) $42 \mathrm{~h}$, and (f) $44 \mathrm{~h}$. 

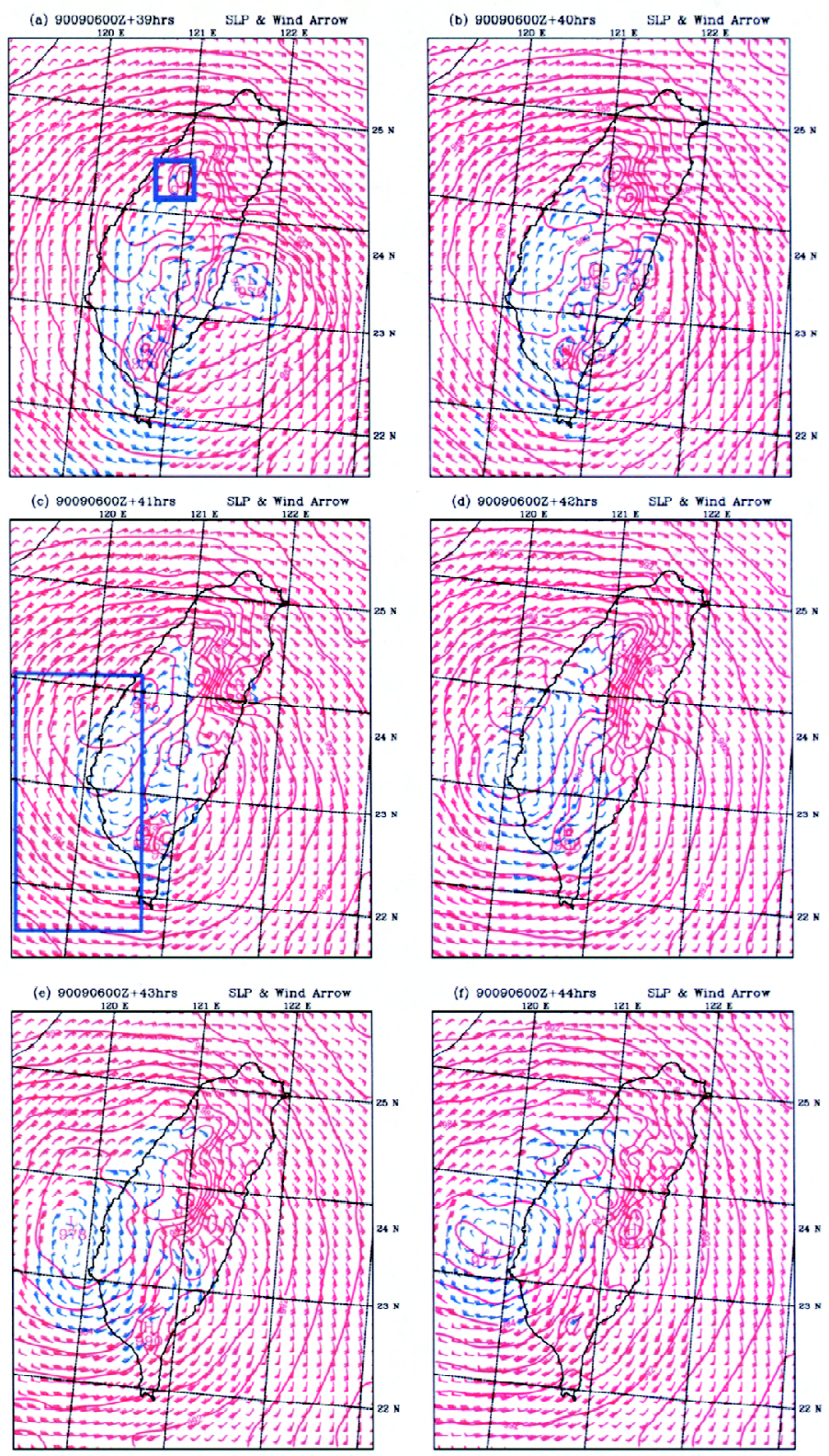

Fig. 7. Distributions of simulated horizontal wind (red color for wind speeds greater than $20 \mathrm{~m} \mathrm{~s}^{-1}$ ) and sea-level pressure (contour interval of $2 \mathrm{hPa}$ ) from the finest (5-km) mesh at (a) $39 \mathrm{~h}$, (b) $40 \mathrm{~h}$, (c) $41 \mathrm{~h}$, (d) $42 \mathrm{~h}$, (e) $43 \mathrm{~h}$, and (f) $44 \mathrm{~h}$. The bold square box in (a) indicates the region for the area average used in Fig. 9. The bold rectangular box in (c) indicates the region for the analyses used in Figs. 10 and 11. 

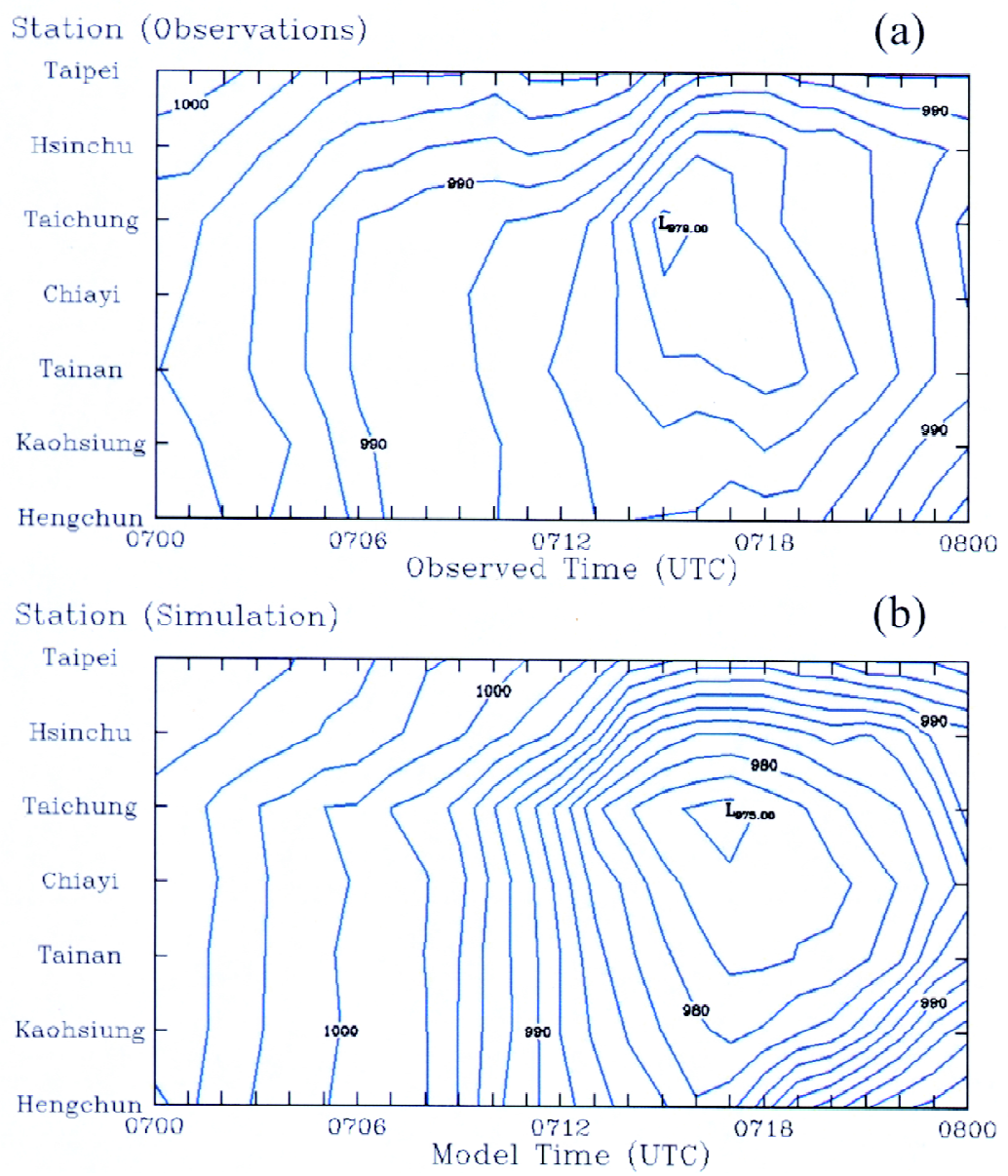

Fig. 8. Time sequences of sea-level pressure with a contour interval of $2 \mathrm{hPa}$ at stations given in the left of the diagrams.

relative humidity decreases during Dot's approach toward Taiwan and increases after its departure, with a minimum of $36 \%$ near $4.5 \mathrm{~km}$ at around $36 \mathrm{~h}$. Below the middle troposphere, a clear and steady drying tendency occurs from $32 \mathrm{~h}$ to shortly before landfall, which is consistent with the warming tendency in temperature (Fig. 9a). The results suggest that, similar to some previous studies (Wang 1980; Bender et al. 1987; Du and Chen 1992; Yeh and Elsberry 1993b), the adiabatic subsidence warming process is the primary contributing factor to the formation of the low-pressure region. Warming developed on the leeside of the CMR when prevailing easterly winds increased as Dot approached Taiwan.

The region of low pressure is essentially a mesoscale system though its size is difficult to measure precisely. It can be expected that the scale of the low-pressure region $\left(\sim 10^{5} \mathrm{~m}\right)$ is smaller than the Rossby radius of deformation $\left(\sim 10^{6} \mathrm{~m}\right)$ in the tropical cyclonic environment 
(a) Temperature

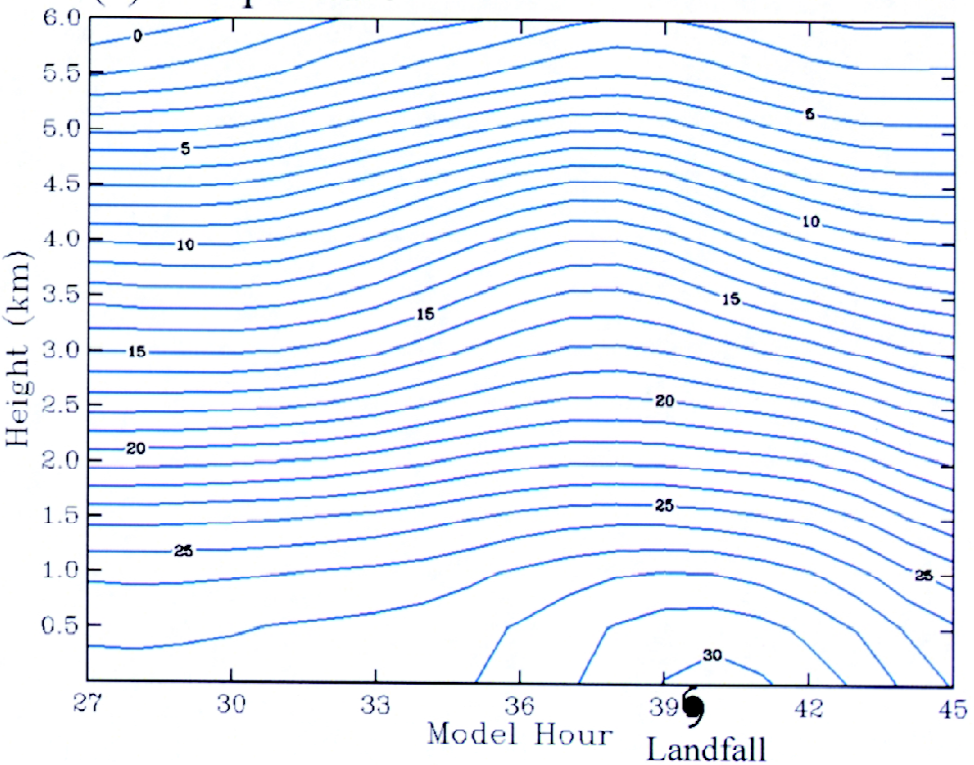

(b) Relative Humidity

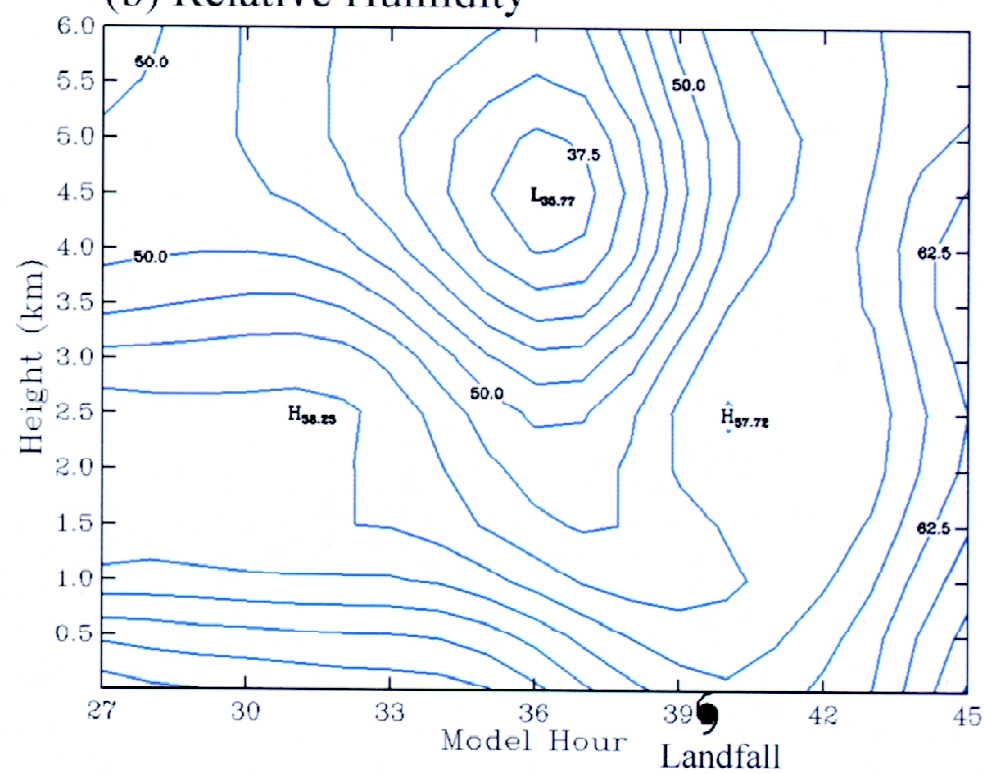

Fig. 9. Time-height cross sections of (a) temperature (contour interval of $1^{\circ} \mathrm{C}$ ), and (b) relative humidity (contour interval of 5\%) averaged over the region near the leeside low-pressure system (as indicated in Fig. 7a) from the finest $(5-\mathrm{km})$ mesh. 
(Ooyama 1982). Under this condition, the geostrophic adjustment processes imply that buoyancy forces dominate rotational effects and the flow over the leeside low-pressure system is controlled by gravity forces. In addition, the scale of the leeside low-pressure system is larger than the stretched induced secondary vortex (Fig. 7). The scale reduction process during the secondary vortex formation is an interesting topic for future investigation.

In order to understand the physical processes that contribute to the formation and development of the dominant secondary vortex, low-level vorticity and divergence fields during the time $39.5 \mathrm{~h}$ to $41.0 \mathrm{~h}$ at 0.5 -h intervals are shown in Fig. 10. About $1.5 \mathrm{~h}$ before the secondary vortex formed (i.e., $39.5 \mathrm{~h}$; Fig. 10a) over southwestern Taiwan, the maximum simulated vorticity exceeds $5.5 \times 10^{-4} \mathrm{~s}^{-1}$ and is located about $20 \mathrm{~km}$ north of the secondary vortex center (represented by the star symbol in Fig. 10). This maximum vorticity area is dominated by the horizontal shear and mainly induced by the wind speed difference between those in the Taiwan Strait and the sheltered area, located on the leeside of the CMR. During the next hour (i.e., $40.0 \mathrm{~h}$ and $40.5 \mathrm{~h}$; Figs. 10b, c), the positive vorticity area shifts southward and collocates with the horizontal convergence region (Figs. 10f, g). Thus, the dominant secondary vortex forms near the southwestern coast.

A vorticity budget may be used to diagnose the physical processes of the secondary vortex formation. The local vorticity tendency equation in sigma coordinates can be written as:

$$
\begin{aligned}
\frac{\partial \zeta}{\partial t}= & -\stackrel{r}{V} \cdot \nabla(\xi+f)-\dot{\sigma} \frac{\partial \zeta}{\partial \sigma}-(\xi+f) \nabla \cdot V \\
& -\left(\frac{\partial \dot{\sigma}}{\partial x} \frac{\partial v}{\partial \sigma}-\frac{\partial \dot{\sigma}}{\partial y} \frac{\partial u}{\partial \sigma}\right)+\left[\frac{\partial}{\partial x}\left(\sigma \frac{\partial \ln p_{*}}{\partial y} \frac{\partial \Phi}{\partial \sigma}\right)-\frac{\partial}{\partial y}\left(\sigma \frac{\partial \ln p_{*}}{\partial x} \frac{\partial \Phi}{\partial \sigma}\right)\right]
\end{aligned}
$$

where $\mathrm{p}^{*}=\mathrm{p}_{\mathrm{s}}-\mathrm{p}_{\mathrm{t}}\left(\mathrm{p}_{\mathrm{s}}\right.$ and $\mathrm{p}_{\mathrm{t}}$ are the surface and top pressures of the model, respectively). The terms on the right-hand side are contributions due to the horizontal advection of absolute vorticity, the vertical advection, vorticity produced by the convergence effect (stretching term), the twisting (tilting) term, and the solenoidal term.

Figure 11 shows the low-level vorticity budget at $40.5 \mathrm{~h}$ (about $0.5 \mathrm{~h}$ before the secondary vortex formation). The analyzed results reveal that the vortex stretching process (Fig. 11c), caused by the superposition of the positive vorticity and the convergence region over southwestern Taiwan (see Figs. 10c, g), is the major producer of the positive vorticity tendency. The horizontal advection, vertical advection, tilting effect, and solenoidal term have relatively smaller contributions. In summary, the dominant secondary vortex in Typhoon Dot's simulation is formed owing to low-level flow near southwestern Taiwan being blocked and producing significant horizontal wind shear, and an area of strong low-level convergence over the southwestern coast. These mesoscale circulation variations make the stretching effect the major positive contributor to the secondary vortex formation during Dot's approach toward Taiwan. The formation scenario in this case study appears to be similar to the idealized simulation in Yeh and Elsberry (1993b), where a weak vortex moving at about $5 \mathrm{~m} \mathrm{~s}^{-1}$ approaches the southeastern part of the barrier. 

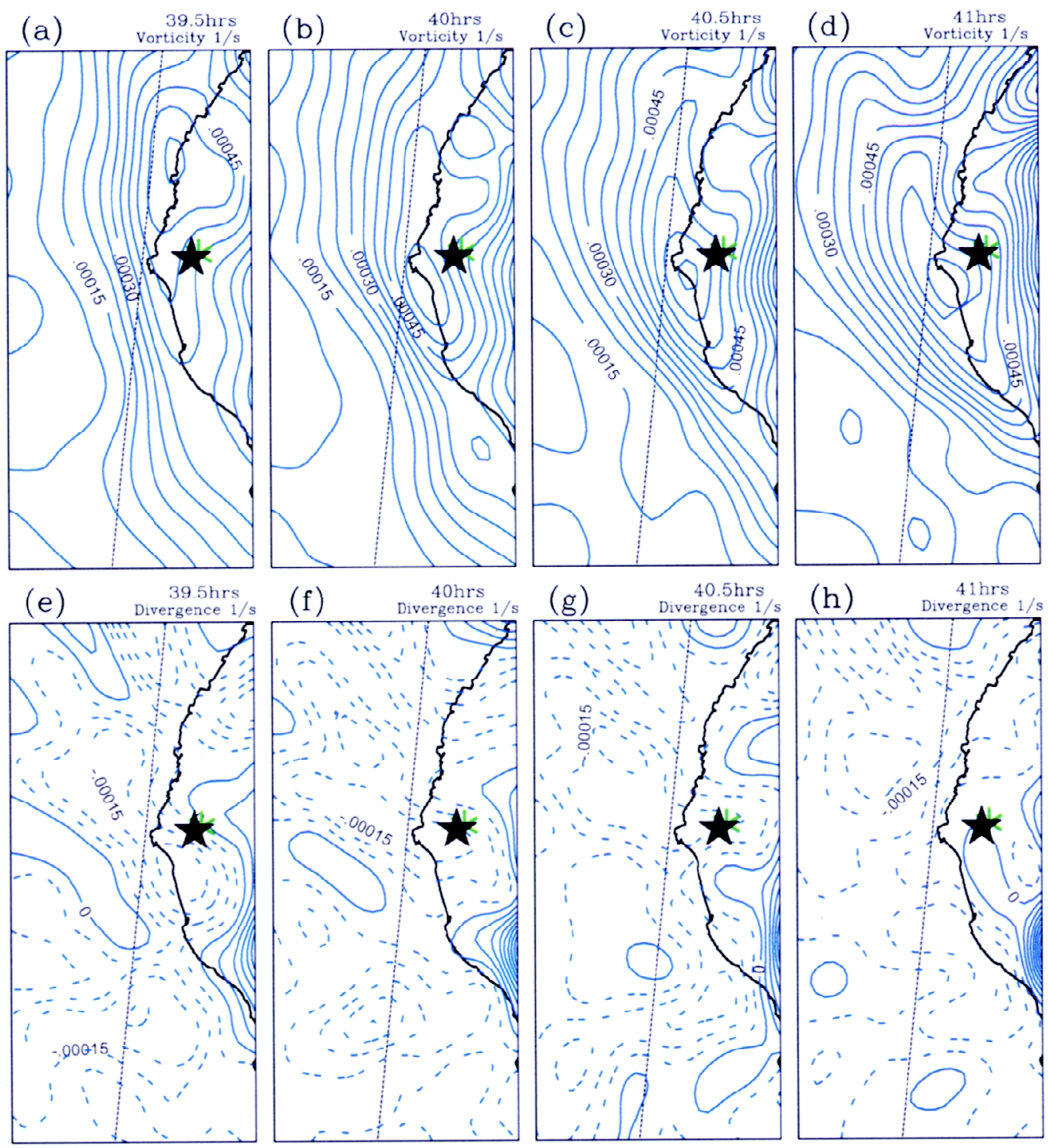

Fig. 10. The simulated low-level relative vorticity fields with a contour interval of $5 \times 10^{-5} \mathrm{~s}^{-1}$ at (a) $39.5 \mathrm{~h}$, (b) $40.0 \mathrm{~h}$, (c) $40.5 \mathrm{~h}$, and (d) $41.0 \mathrm{~h}$ and the horizontal divergence fields with a contour interval of $5 \times 10^{-5} \mathrm{~s}^{-1}$ at (e) $39.5 \mathrm{~h}$, (f) $40.0 \mathrm{~h}$, (g) $40.5 \mathrm{~h}$, and (h) $41.0 \mathrm{~h}$. The star symbol shows the location of the formed secondary vortex. 

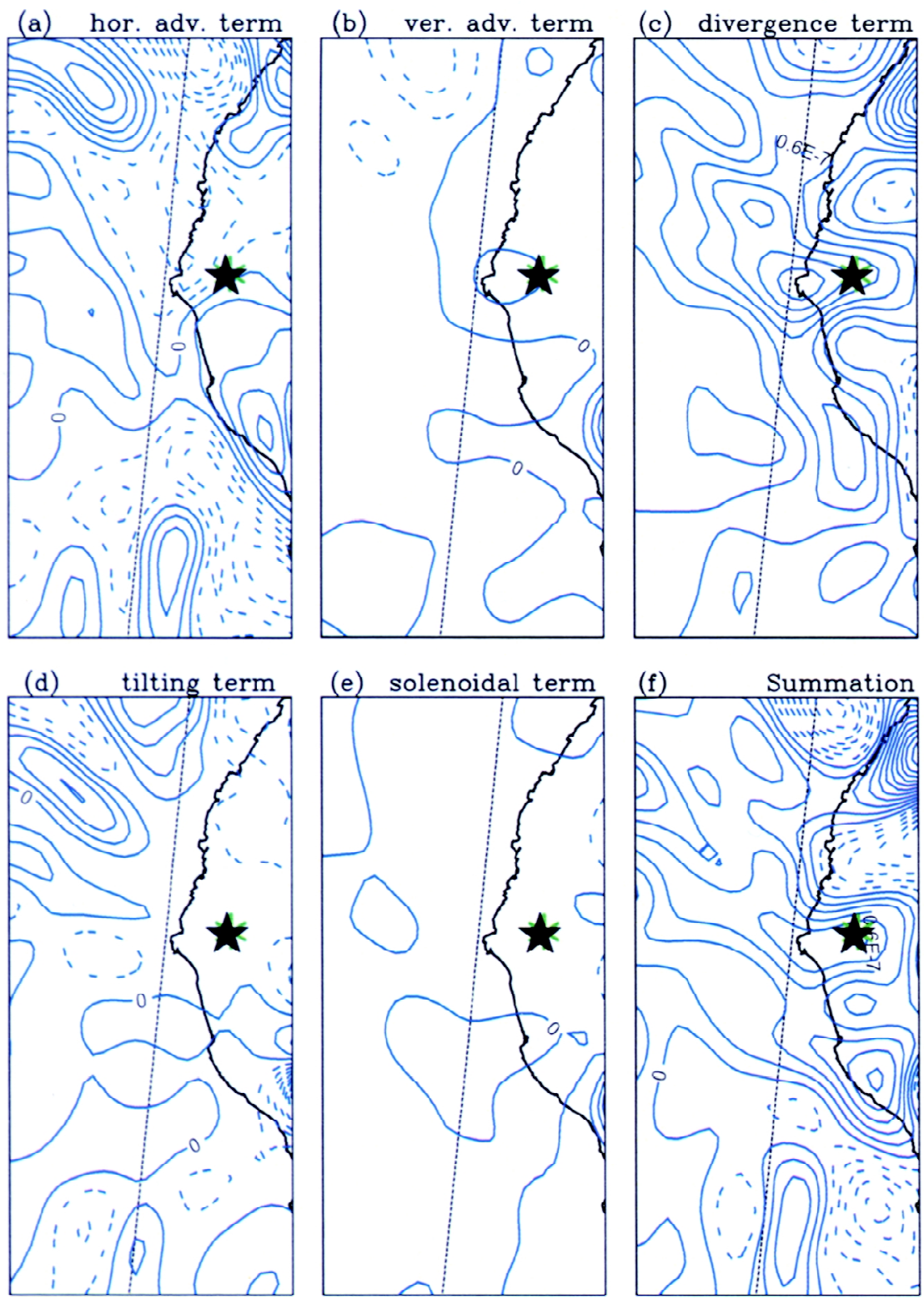

Fig. 11. Distributions of simulated (a) horizontal advection, (b) vertical advection, (c) stretching (divergence) effect, (d) tilting, (e) solenoidal, and (f) summation (represents the local vorticity tendency) terms in the vorticity budget at low-level at $40.5 \mathrm{~h}$. Contour interval is $2 \times 10^{-8} \mathrm{~s}^{-2}$. 


\section{RECONFIGURATION OF NEW TYPHOON CENTER}

Tsay et al. (1995) and Shieh et al. (1998) documented an interesting cyclonic looping track when the dominant secondary vortex developed and moved toward the Taiwan Strait. In this section, we will examine the physical processes of the looping track. Figure 12 shows the mid-level mean streamlines (averaged for sigma levels 0.825 to 0.675 ) from the 5-km-resolution domain during the time $38 \mathrm{~h}$ to $44 \mathrm{~h}$ at 2 -h intervals. In contrast to the low-level flow, it is found that the path of the vortex center at the mid-level is continuous as it crosses the CMR. This fact can be roughly verified by examining the observed wind directions at Yu-Shan $\left(23.3^{\circ} \mathrm{N}, 120.6^{\circ} \mathrm{E} ; 3854 \mathrm{~m}\right.$ altitude; see Fig. 1 for location $)$ and A-Li-Shan $\left(23.3^{\circ} \mathrm{N}, 120.5^{\circ} \mathrm{E}\right.$; $2413 \mathrm{~m}$ altitude; see Fig. 1 for location) in Fig. 3. The wind directions turning from northerly at 1200 UTC 7 September (Fig. 3b) to easterly at 1600 UTC 7 September (Fig. 3f) suggest that the mid-level-vortex center passed to the south of these two stations during the period when the secondary vortex developed over southwestern Taiwan. In general, the simulated flow in Fig. 12 agrees well with the observed wind directions change and indicates a continuous path across Taiwan.

The interaction of simulated tracks between the dominant secondary vortex and the midlevel-vortex is shown in Fig. 13. The mid-level-vortex center passes over the CMR and approaches the secondary vortex center as it moved from the island into the Taiwan Strait. Over the next several hours, they converged toward each other with a southward deflection by the mid-level center and a cyclonic looping path by the low-level secondary vortex center. To track the relative paths of the two vortices, the centroid-relative motion can be used. However, it is difficult to identify the centroid of the mid-level and secondary vortices in our case study. To simplify this analysis we define the tracks of the two vortices as the paths of their geometric centers as seen in plane view. The results shown in Fig. 13 indicate that the merging of the mid-level and secondary vortices is accompanied by a cyclonic rotation of one vortex geometry relative to the other. The interaction can be examined further with a set of backward trajectories calculated for an 8-h period ending at $46 \mathrm{~h}$ (valid time from 1400 UTC to 2200 UTC 7 September) and shown in Fig. 14. The parcels are released at sigma levels 0.6, 0.7, 0.8, and 0.9. The backward trajectory of an air parcel is obtained by computing the horizontal and vertical displacement of the air parcel for each time step, $\delta \mathrm{t}$. To compute the three-dimensional displacement during the time interval $(\mathrm{t}, \mathrm{t}+\delta \mathrm{t})$, an iterative scheme is used:

$$
X_{\mathrm{n}+1}=\boldsymbol{X}_{0}+0.5 \cdot\left[v\left(\boldsymbol{X}_{0}, \mathrm{t}\right)+v\left(\boldsymbol{X}_{\mathrm{n}}, \mathrm{t}+\delta \mathrm{t}\right)\right] \cdot \delta \mathrm{t},
$$

where $\boldsymbol{X}_{0}$ is the position vector of the parcel at time $\mathrm{t}, \boldsymbol{X}_{\mathrm{n}}$ is the nth iterative approximation of the position vector at $\mathrm{t}+\delta \mathrm{t}$, and $v(\boldsymbol{X}, \mathrm{t})$ is the three dimensional wind vector at position $\boldsymbol{X}$ and time t.

Figure 14 shows that some parcels arriving at the mid-level (parcels 3, 4 at 0.6, 0.7 sigma levels; Figs. 14a, b) have been borne on easterly flow passing directly over the CMR. The trajectories at low-level (Figs. 14c, d), however, indicate that most parcels have been transported by northeasterly flow around the north side of Taiwan and exhibited cyclonic histories near the secondary vortex center. As a result, we suggest that the observed looping track ex- 
(a) $90090600 \mathrm{Z}+38 \mathrm{hrs} \quad$ Streamline

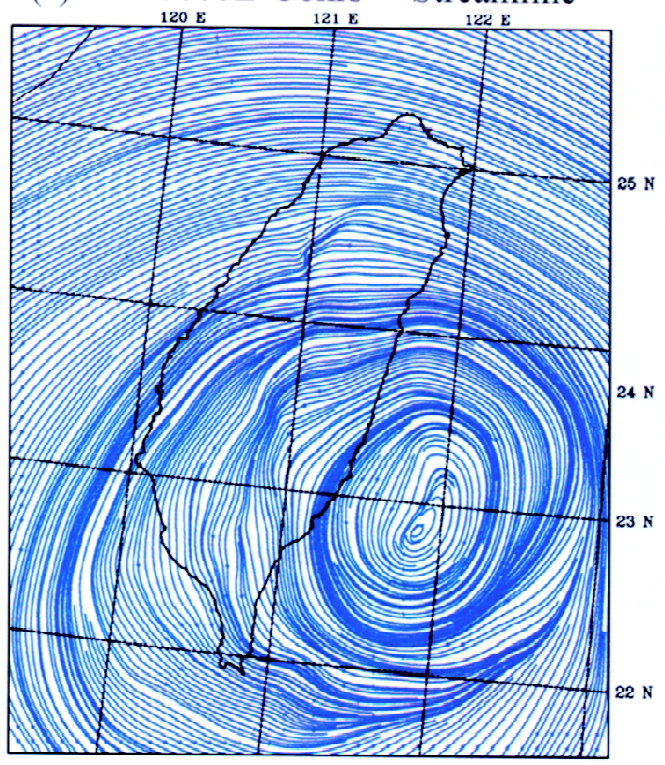

(c) $90090600 \mathrm{Z}+42 \mathrm{hrs} \quad$ Streamline

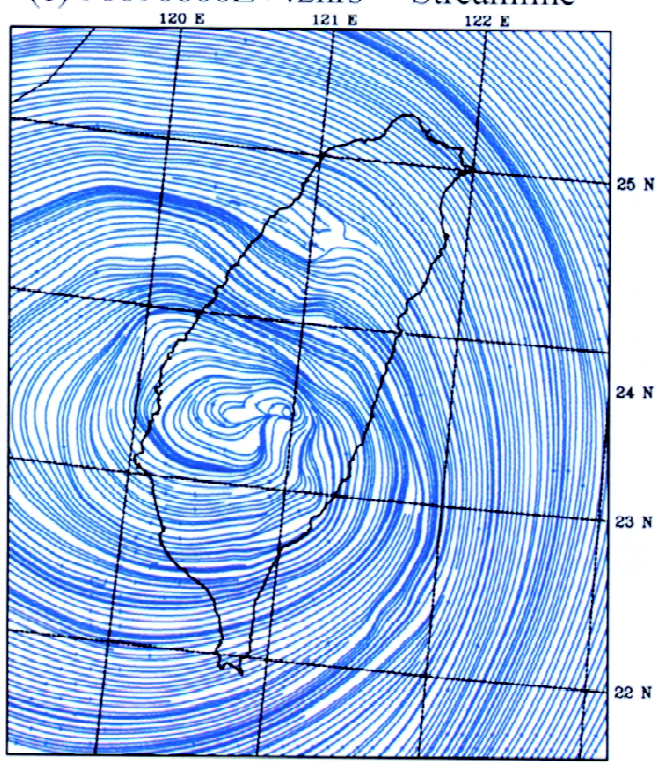

(b) $90090600 \mathrm{Z}+40 \mathrm{hrs} \quad$ Streamline

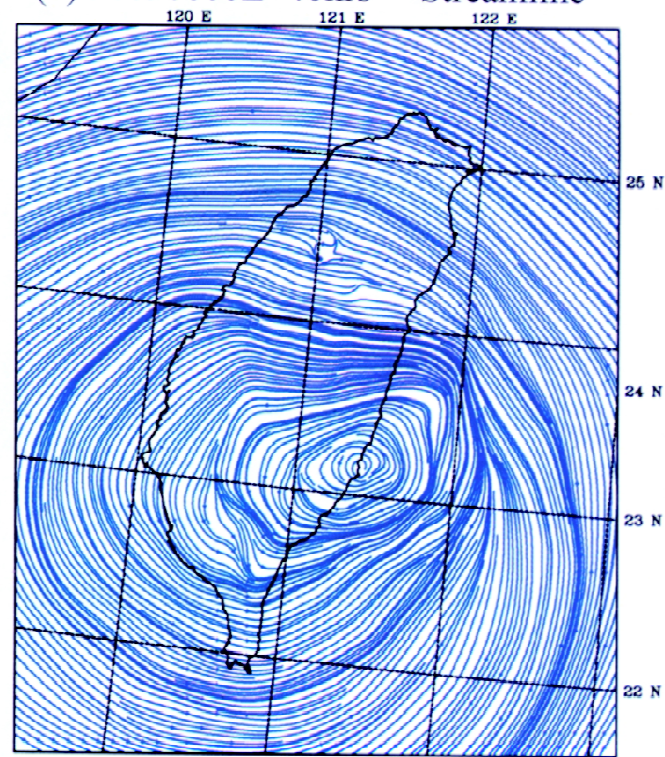

(d) $90090600 \mathrm{Z}+44 \mathrm{hrs} \quad$ Streamline

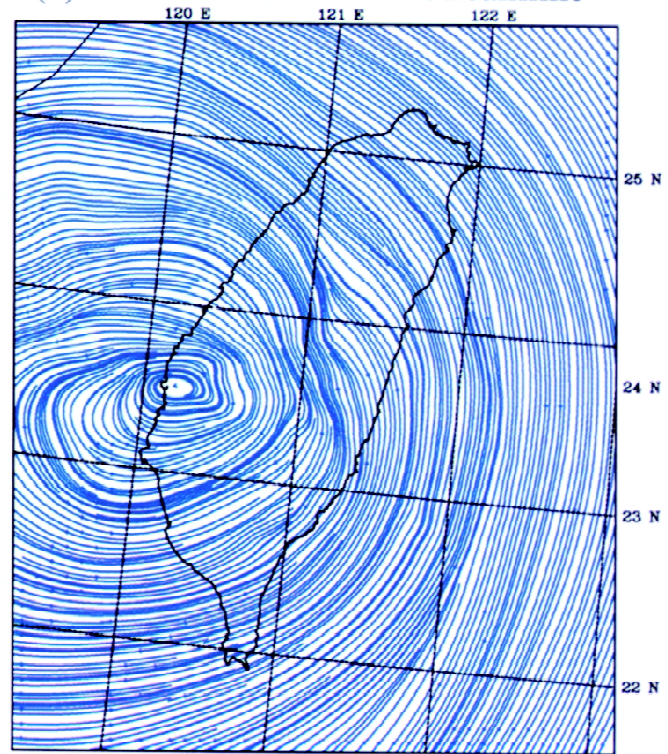

Fig. 12. The simulated middle-level streamlines from the finest $(5-\mathrm{km})$ mesh at (a) $38 \mathrm{~h}$, (b) $40 \mathrm{~h}$, (c) $42 \mathrm{~h}$, and (d) $44 \mathrm{~h}$. 


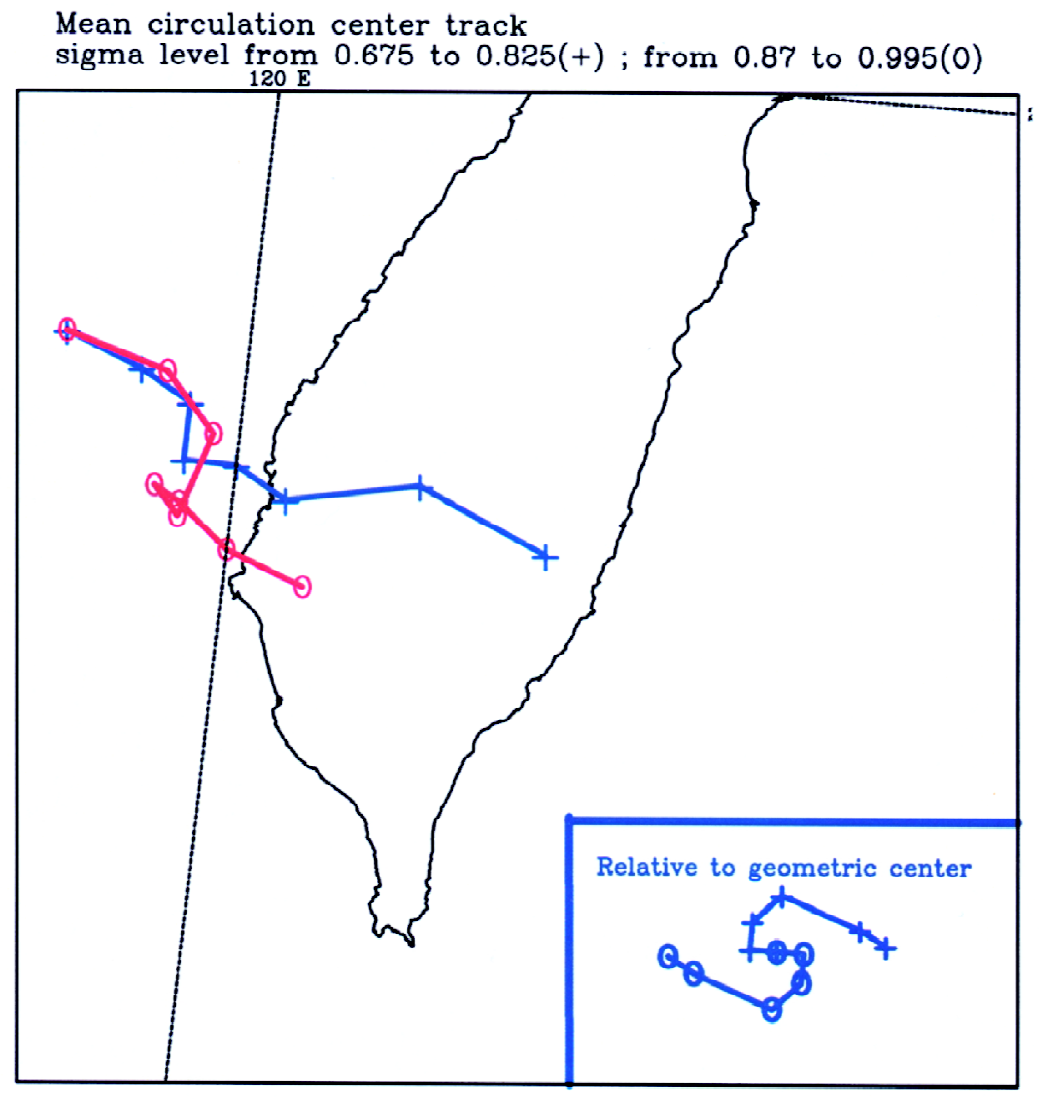

Fig. 13. The simulated tracks of the mid-level (plus signs) and secondary (open circles) vortices. The geometrically-relative motion is also shown.

ecuted by Typhoon Dot was due to the interaction between the mid-level and low-level secondary vortices. When these vortices finally become superimposed vertically, the new typhoon center is formed. This discussion about the mutual cyclonic rotation of the upper level and lower level vortices is based solely on simulation results since upper level observations are relatively sparse over Taiwan area.

\section{DISCUSSIONS AND CONCLUSIONS}

The objective of this paper was to investigate the physical processes that occurred during the discontinuous track Typhoon Dot's passage over Taiwan, using the PSU-NCAR MM5 initialized with TCM-90 datasets. A numerical simulation was performed over a 48-h period beginning at 0000 UTC 6 September 1990. Typhoon Dot followed a very straight track as it 
(a) Trajectories aros roleasod at to.0 hours at sigma $=0.00$

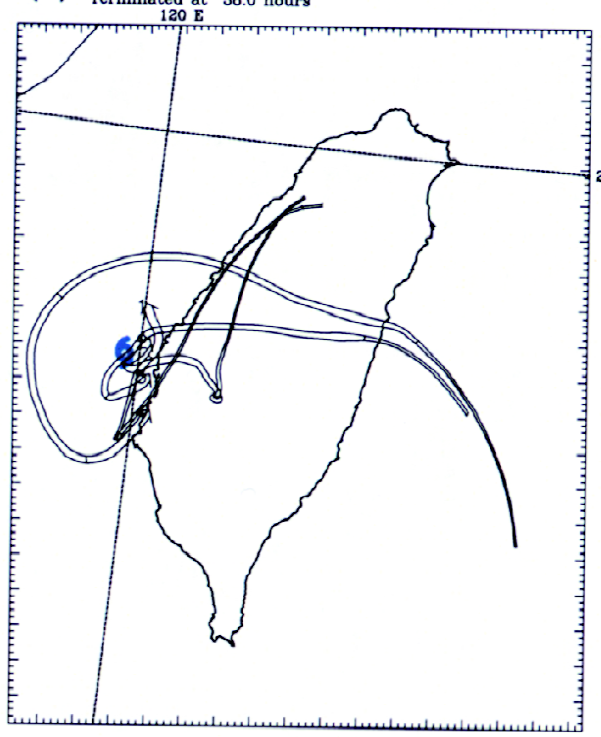

(c) Trajectories are released at 46.0 hours at sigma $=0.80$

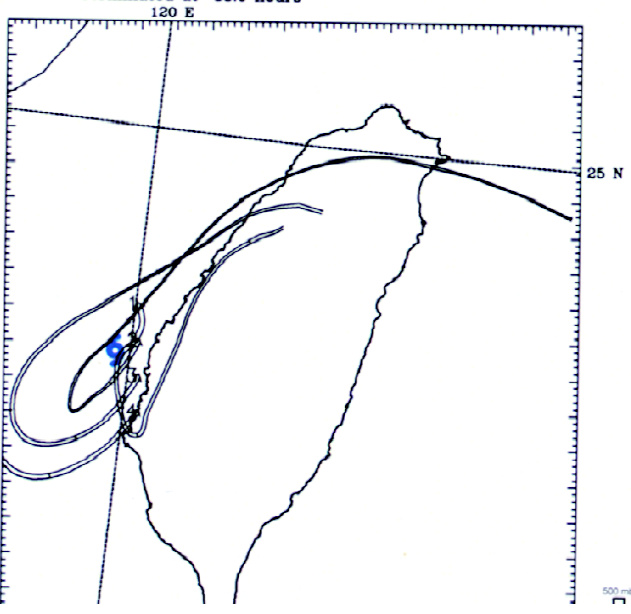

(b) Trajectories are released at 48.0 hours at sigma $=0.70$

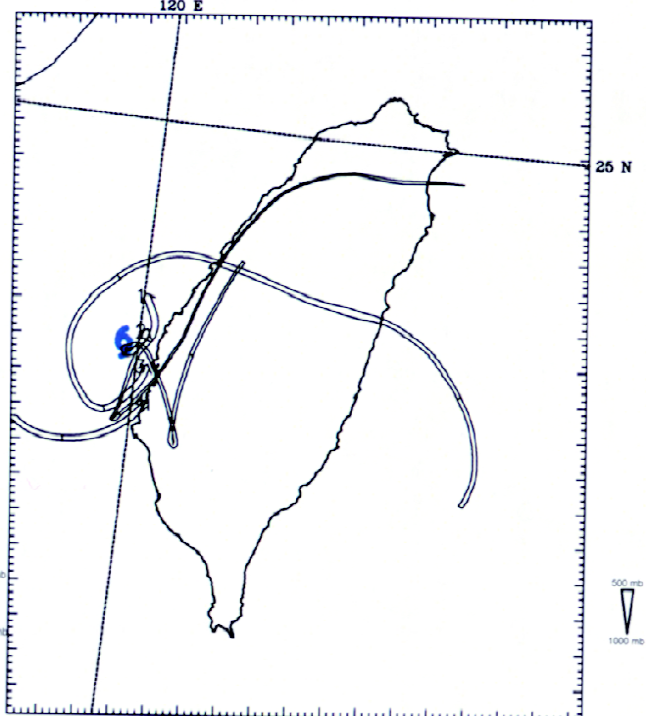
(d) Trajectories are released at 48.0 hours at sigma $=0.90$

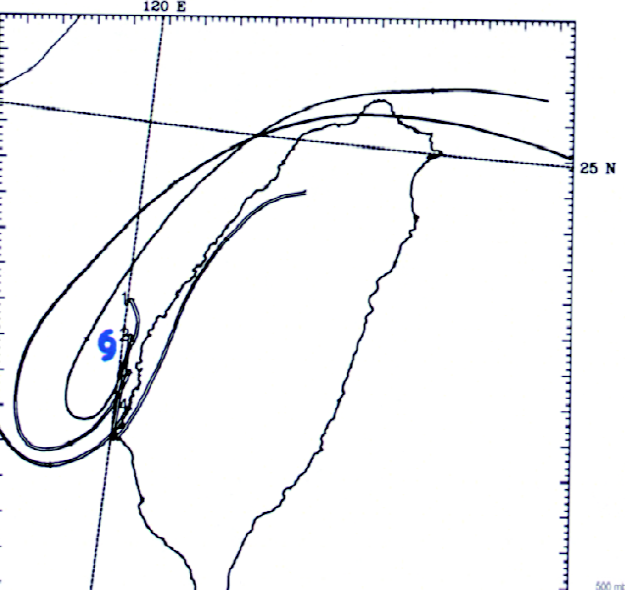

Fig. 14. Backward trajectories based on MM5 simulated winds from the finest (5-km) mesh. Parcels are released from (a) 0.6, (b) 0.7, (c) 0.8 , and (d) 0.9 sigma levels at 2200 UTC 7 September 1990 and calculated backward for $8 \mathrm{~h}$. Width of the trajectories depicts transport level between 1000 and $500 \mathrm{hPa}$. 
approached Taiwan and made landfall on the southeastern shoreline. During the period when Dot passed over the island, mesoscale analyses from observations showed that a dominant secondary vortex formed near southwestern Taiwan. It subsequently developed and became the main typhoon center, replacing the original center that dissipated on the eastern coast. Another interesting feature was the cyclonic looping track when the new typhoon center developed and moved toward the Taiwan Strait. The primary emphasis of this study is to understand the physical processes of these phenomena associated with Dot's passage across Taiwan.

Through the analysis of observations and numerical results, a three-dimensional conceptual model of Typhoon Dot's interaction with Taiwan has emerged and is shown schematically in Fig. 15. When Dot was centered over the sea southeast of Taiwan (system O in Fig. 15), the easterly flow in the northern quadrant of typhoon circulation crossed the CMR. The resultant downslope wind warmed adiabatically on the leeside and induced a region of low pressure over the central part of western Taiwan (system L in Fig. 15a). During the next several hours, a dominant secondary vortex (system C in Fig. 15) formed by a vortex stretching process, which was induced by the significant positive shear vorticity collocating with a convergence region near the southwestern coast of Taiwan. After Dot made landfall, the original low-level typhoon vortex was blocked, weakened, and gradually dissipated on the eastern side of the CMR, whereas the mid-level vortex (system U in Fig. 15b) passed over Taiwan with a continuous path. When the mid-level vortex approached the newly formed secondary vortex, they converged toward each other, resulting in a southward deflection being executed by the mid-level vortex, and a cyclonic looping path being executed by the secondary vortex (see Fig. 15b). The merging mid-level and secondary vortices coupled vertically and subsequently became a newly reconfigured Typhoon Dot (system N in Fig. 15b) as it continued its northwest journey.

In the Typhoon Dot case study, the high-resolution mesoscale model shows reasonable simulation results for track and local circulation variations over the Taiwan area as compared to observations. Since both the vortex Froude number $\left(V_{\max } / N h\right)$ and the ratio of typhoon scale to mountain scale $\left(R / L_{y}\right)$ are small, Dot passed over Taiwan discontinuously. This result suggests that the control parameters of Typhoon Dot simulation agree with the argument of Lin et al. (2005). However, the physical mechanisms are very complicated during a typhoon affecting Taiwan, and we acknowledge that there are still some questions and further work warranted, especially for the detailed physical mechanisms of the formation of the secondary vortex. Efforts are ongoing to understand the driving mechanism of the stretching process. This driving mechanism is the critical factor in determining the position of the secondary vortex formation. In addition, disparities in the respective scales of the leeside low-pressure system (large) versus the secondary vortex (small) is of intense interest. How its scale reduction occurs requires future investigation.

Acknowledgements The authors would like to thank Dr. Y. L. Lin at North Carolina State University and Dr. J. A. McGinley at the NOAA/FSL for their valuable discussions. Some figure plotting by Ms. S. Y. Liou is also appreciated. The authors are grateful to two anonymous reviewers for their insightful comments that substantially improved the original manuscript. This research was supported by the National Science Council of Taiwan under grants NSC 90-2111-M-002-028-AP4, NSC91-2111-M-002-016, and NSC94-2625-Z-052-008. 

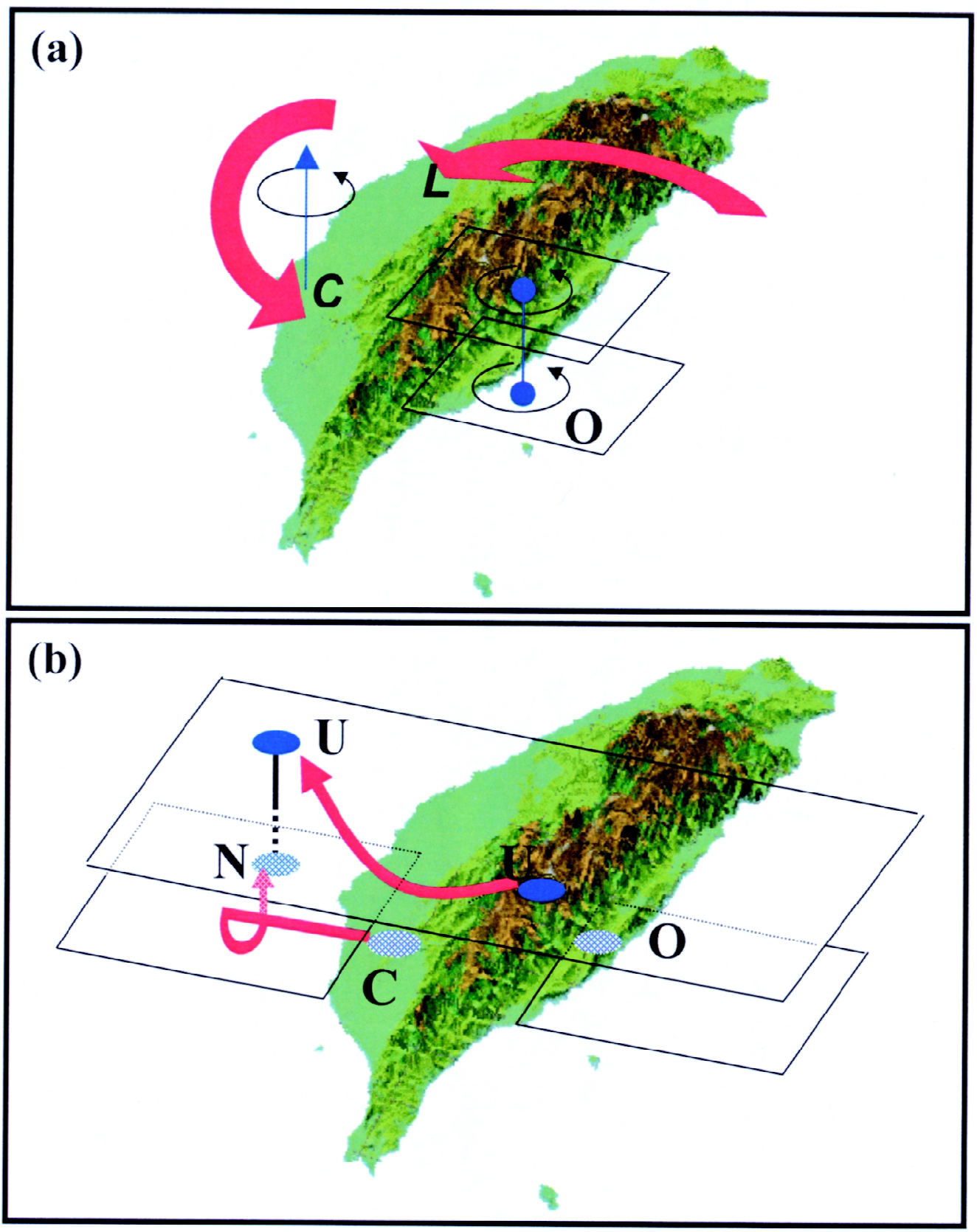

Fig. 15. Schematic diagram showing a conceptual model of the mesoscale evolution during Typhoon Dot (1990) across Taiwan. Details are discussed in section 6 . 


\section{REFERENCES}

Baik, J. J., M. DeMaria, and S. Raman, 1990: Tropical cyclone simulations with the Betts convective adjustment scheme. Part I: Model description and control simulation.Mon. Wea. Rev., 118, 513-528.

Bender, M. A., R. E. Tuleya, and Y. Kurihara, 1987: A numerical study of the effect of island terrain on tropical cyclones. Mon. Wea. Rev., 115, 130-155.

Betts, A. K., 1986: A new convective adjustment scheme. Part I: Observational and theoretical basis. Quart. J. Roy. Meteor. Soc., 112, 677-691.

Betts, A. K., and M. J. Miller, 1986: A new convective adjustment scheme. Part II: Single column tests using GATE wave, BOMEX, ATEX and arctic air-mass data sets. Quart. J. Roy. Meteor. Soc., 112, 693-709.

Blackadar, A. K., 1979: High resolution models of the planetary boundary layer. Advances in Environmental Science and Engineering, 1, No. 1. In: Pfafflin and Ziegler, (Eds.), Gordon and Briech Sci. Publ., New York, 50-85.

Brand, S., and J. W. Blelloch, 1974: Changes in the characteristics of typhoons crossing the island of Taiwan. Mon. Wea. Rev., 102, 708-713.

Chang, C. P., T. C. Yeh, and J. M. Chen, 1993: Effects of terrain on the surface structure of typhoons over Taiwan. Mon. Wea. Rev., 121, 734-752.

Chang, S. W., 1982: The orographic effects induced by an island mountain range on propagating tropical cyclones. Mon. Wea. Rev., 110, 1255-1270.

Cressman, G., 1959: An operational objective analysis system. Mon. Wea. Rev., 87, 367-374.

Du, F. H, and G. T. J. Chen, 1992: The diagnostic analyses of Typhoon Dot (1990) during TATEX (in Chinese). Conf. on Wea. Anal. and Forecasting, Taipei, Cent. Wea. Bureau, 243-252.

Dudhia, J., 1989: Numerical study of convection observed during the Winter Monsoon Experiment using a mesoscale two-dimensional model. J. Atmos. Sci., 46, 3077-3107.

Dudhia, J., 1993: A nonhydrostatic version of the Penn State-NCAR Mesoscale Model: Validation tests and simulation of an Atlantic cyclone and cold front.Mon. Wea.Rev., 121, 1493-1513.

Elsberry, R. L., 1990: International experiments to study tropical cyclones in the western North Pacific. Bull. Am. Meteor. Soc., 71, 1305-1316.

Grell, G. A., J. Dudhia, and D. R. Stauffer, 1994: A description of the Fifth-Generation Penn State/ NCAR Mesoscale Model (MM5). NCAR Tech. Note, NCAR/TN-398+STR, 122 pp.

Jian, G. J., and C. S. Lee, 2002: A numerical simulation and analysis of Typhoon Yancy (1990) during its landfall on Taiwan. J. Atmos. Sci., 30, 147-170. (in Chinese with English Abs.)

Kuo, H. L., 1974: Further studies of the parameterization of the effect of cumulus convection on large scale flow. J. Atmos. Sci., 31, 1232-1240.

Kuo, Y. H., and W. Wang, 1997: Rainfall prediction of Typhoon Herb with a mesoscale model. Preprints, Workshop on Typhoon Research in the Taiwan Area. Boulder, CO, Nat. Sci. Coun., 35-45. 
Lin, Y. L., J. Han, D. W. Hamilton, and C. Y. Huang, 1999: Orographic influence on a drifting cyclone. J. Atmos. Sci., 56, 534-562.

Lin, Y. L., D. B. Ensley, S. Chiao, and C. Y. Huang, 2002: Orographic influences on rainfall and track deflection associated with the passage of a tropical cyclone.Mon. Wea.Rev., 130, 2929-2950.

Lin, Y. L., S. Y. Chen, C. M. Hill, and C. Y. Huang, 2004: Control parameters for track continuity and deflection associated with a drifting cyclone over a mesoscale mountain. Submitted for publication.

Ooyama, K., 1982: Conceptual evolution of the theory and modeling of the tropical cyclone. J. Meteor. Soc. Japan, 60, 369-379.

Puri, K., and M. J. Miller, 1990: Sensitivity of ECMWF analyses-forecasts of tropical cyclones to cumulus parameterization. Mon. Wea. Rev., 118, 1709-1741.

Shieh, S. L., S. T. Wang, M. D. Cheng, and T. C. Yeh, 1998: Tropical cyclone tracks over Taiwan from 1897 to 1996 and their applications. Cent. Wea. Bureau Res. Rep. CWB861M-01, 497 pp. (in Chinese)

Tsay, C. Y., S. T. Wang, and M. D. Cheng, 1995: User's guide for typhoon forecasting in the Taiwan area. Cent. Wea. Bureau Res. Rep. CWB83-1M-01, 370 pp. (in Chinese)

Wang, S. T., 1980: Prediction of the behavior and intensity of typhoons in Taiwan and its vicinity. Research Rep., 018, National Science Council, Taipei, Taiwan, 100 pp. (in Chinese)

Wu, C. C., and Y. H. Kuo, 1999: Typhoons affecting Taiwan: Current understanding and future challenges. Bull. Am. Meteor. Soc., 80, 67-80.

Wu, C. C., 2001: Numerical simulation of Typhoon Gladys (1994) and its interaction with Taiwan terrain using the GFDL hurricane model. Mon. Wea. Rev., 129, 1533-1549.

Wu, C. C., T. H. Yen, Y. H. Kuo, and W. Wang, 2002: Rainfall simulation associated with Typhoon Herb (1996) near Taiwan. Part I: The topographic effect. Wea. Forecasting, 17, 1001-1015.

Yeh, T. C., and R. L. Elsberry, 1993a: Interaction of typhoons with the Taiwan orography. Part I: Upstream track deflections. Mon. Wea. Rev., 121, 3193-3212.

Yeh, T. C., and R. L. Elsberry, 1993b: Interaction of typhoons with the Taiwan orography. Part II: Continuous and discontinuous tracks across the island.Mon. Wea. Rev., 121, 3213-3233.

Zhang, D. L., and R. A. Anthes, 1982: A high-resolution model of the planetary boundary layer - Sensitivity tests and comparisons with SESAME-79 data.J. Appl. Meteo., 21, 1594-1609.

\section{APPENDIX}

Betts and Miller (1986) proposed a convective adjustment scheme that includes deep and shallow convection. For deep convection, it uses an empirically based, quasi-equilibrium, thermodynamic profile as a reference state. The construction of the quasi-equilibrium reference profile and specification of the relaxation time scale are two important components of the 
Betts-Miller scheme. As mentioned by Betts and Miller (1986), the quasi-equilibria are different for different convective regions. Therefore, it is necessary to tune the adjustment parameters for a proper specification of reference profile appropriate for the Taiwan area. The BettsMiller scheme has been applied to the simulation or prediction of tropical cyclones. For example, Baik et al. (1990) found that this scheme is capable of simulating the rapidly intensifying and mature stages of a tropical cyclone. Puri and Miller (1990) indicated the Betts-Miller scheme produced a more intense storm in closer agreement with observations than the Kuo (1974) scheme. In this appendix, we will examine how the model storm intensity and movement are influenced by variations in the convective adjustment parameters.

In sensitivity experiments of the saturation pressure departure, the adjustment time scale $(\tau)$ equal to $1 \mathrm{~h}$ is kept constant, and $\left(S_{b}, S_{f}, S_{t}\right)$ values are varied (see Table A1). The $S_{b}, S_{f}$, and $S_{t}$, are three specified saturation pressure departure values at three levels corresponding to the cloud base, the freezing level, and the cloud-top level, respectively. Three sets of saturation departure values used in this paper are EXPW ( $-44 \mathrm{hPa},-55 \mathrm{hPa},-33 \mathrm{hPa})$, CTRL (-48 $\mathrm{hPa},-60 \mathrm{hPa},-36 \mathrm{hPa})$, and EXPD $(-72 \mathrm{hPa},-90 \mathrm{hPa},-54 \mathrm{hPa})$. The EXPW represents a reference profile that is more moist than the profile used in the control experiment (CTRL). In contrast, the reference profile in EXPD is the driest of all three experiments. Figure A1 shows the tracks and time series of the maximum wind speed at lowest (0.995) sigma level for CTRL, EXPW, and EXPD. In comparisons between simulations, the storm movement is slower in EXPW and faster in EXPD. Moreover, the EXPW has produced a stronger and smaller scale (figures not shown) vortex. Therefore, the storm decay is less during its passage over the CMR (Fig. A1b). In EXPD, the simulated track is more northwestward than in CTRL partly because the simulation produced a bigger (but weaker) storm.

In the sensitivity experiments for the adjustment time scale, the $\left(\mathrm{S}_{\mathrm{b}}, \mathrm{S}_{\mathrm{f}}, \mathrm{S}_{\mathrm{t}}\right)$ values are kept

Table A1. Various convective adjustment parameters in Betts-Miller scheme for the five experiments. The $S_{b}, S_{f}$, and $S_{t}$ represent the saturation pressure departure values at cloud bottom, freezing level, and cloud top, respectively. The $\tau$ represents the adjustment time scale. See appendix for details.

\begin{tabular}{ccccc}
\hline \hline \multirow{2}{*}{ Experiment } & \multicolumn{3}{c}{ Saturation pressure departure } & Time scale \\
\cline { 2 - 5 } & $\mathrm{S}_{\mathrm{b}}(\mathrm{hPa})$ & $\mathrm{S}_{\mathrm{f}}(\mathrm{hPa})$ & $\mathrm{S}_{\mathrm{t}}(\mathrm{hPa})$ & $\tau(\mathrm{h})$ \\
\hline CTRL & -48 & -60 & -36 & 1 \\
EXPW & -44 & -55 & -33 & 1 \\
EXPD & -70 & -90 & -54 & 1 \\
EXPS & -48 & -60 & -36 & 0.5 \\
EXPL & -48 & -60 & -36 & 2 \\
\hline
\end{tabular}



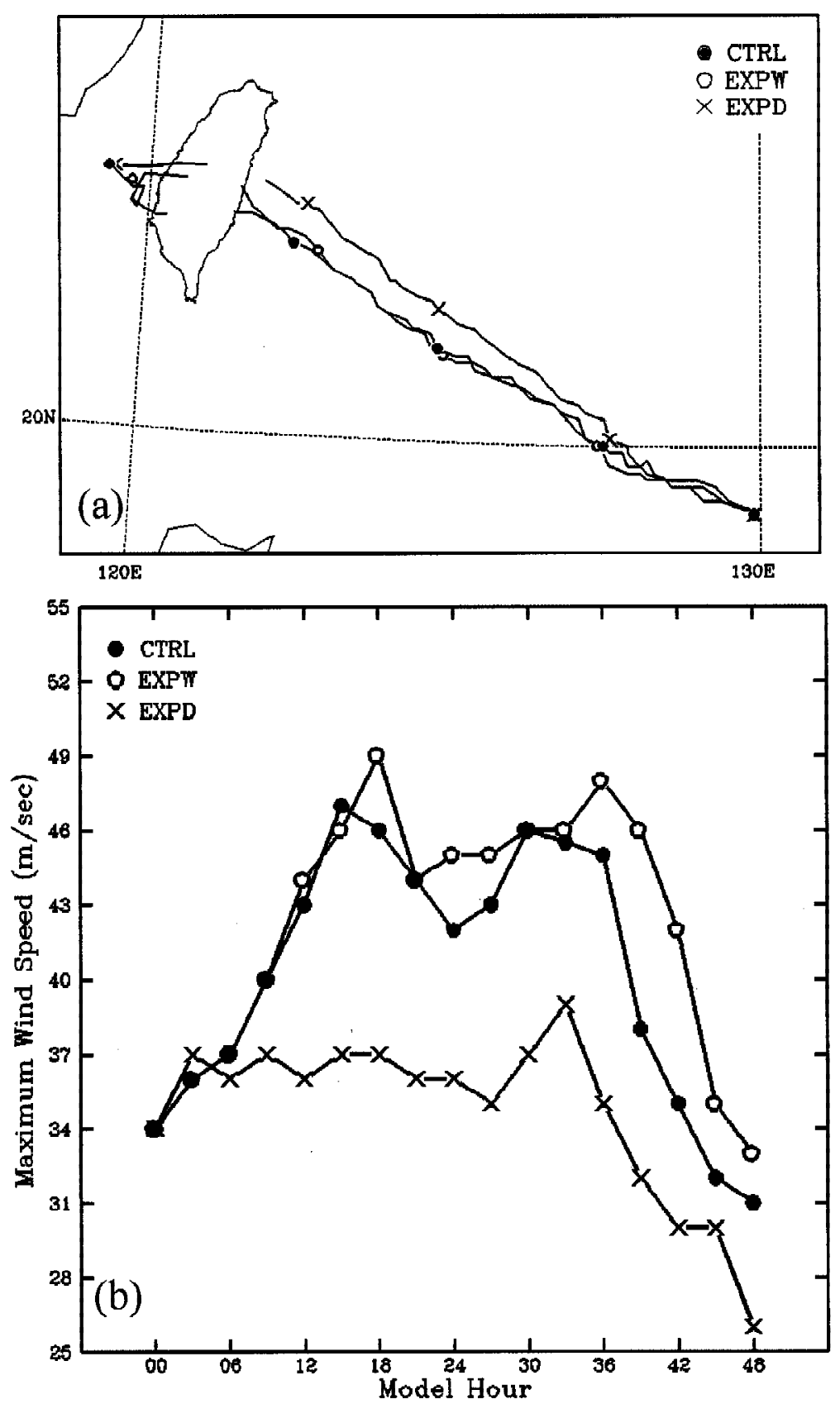

Fig. Al. (a) Storm tracks, and (b) maximum wind speed near surface (in $\mathrm{m} \mathrm{s}^{-1}$ ) at 3-h intervals from the CTRL (filled circles), EXPW (open circles), and EXPD (cross signs) simulations. 

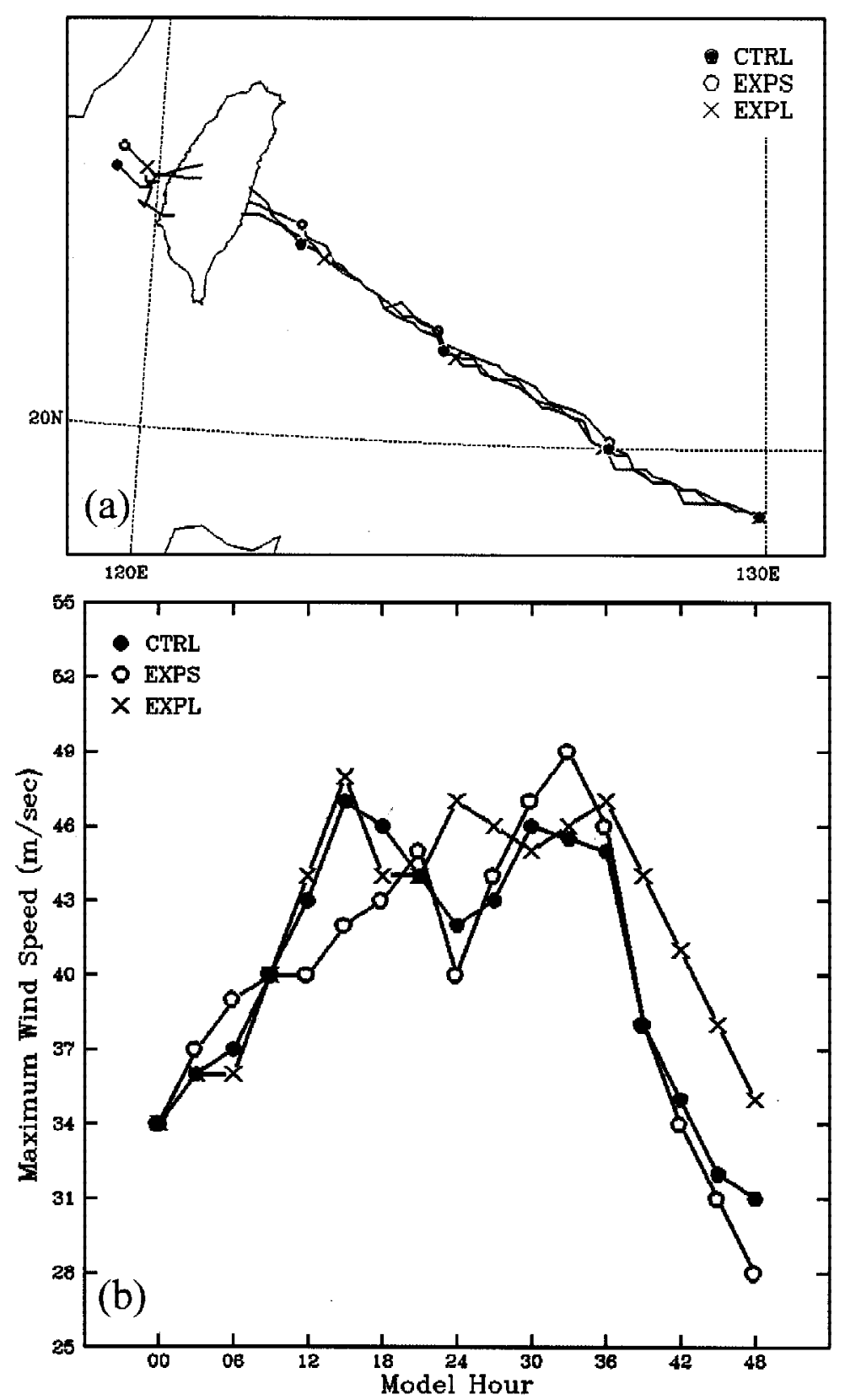

Fig. A2. (a) Storm tracks, and (b) maximum wind speed near surface (in $\mathrm{m} \mathrm{s}^{-1}$ ) at 3-h intervals from CTRL (filled circles), EXPS (open circles), and EXPL (cross signs) simulations. 
constant [equal to $(-48 \mathrm{hPa},-60 \mathrm{hPa},-36 \mathrm{hPa})$ ] and the adjustment time scale $(\tau)$ are $0.5 \mathrm{~h}$, $1 \mathrm{~h}$, and $2 \mathrm{~h}$ for EXPS, CTRL, and EXPL, respectively. The larger adjustment time scale represents a longer time lag between large-scale forcing and convective adjustment. Figure A2 shows that the simulation tracks are similar for all three $\tau$ values except for the storm's slower movement in EXPL. The storm intensity for all three experiments (Fig. A2) are also similar prior to the vortex making landfall. However, the storm decay is somewhat less in EXPL during its passage over the CMR.

The above sensitivity experiments also illustrate that the region of low pressure on the leeside of the CMR is formed by terrain-locked subsidence warming, and thus does not move downstream. However, a lower minimum pressure is found in EXPD due to the drier reference profile. The development of the secondary vortex in EXPD is also earlier than the other sensitivity experiments. Therefore, the typhoon center is replaced by the secondary vortex before the original center has even made landfall (see Fig. A1a). These sensitivity experiments suggest that it is necessary to choose a suitable set of adjustment parameters for typhoon simulation near Taiwan. In the Typhoon Dot case study, the model storm behavior is more sensitive to the saturation pressure departure values compared to the adjustment time scale. 